\title{
Pinch Methods for Efficient Use of Water in Food Industry: A Survey Review
}

\author{
Keivan Nemati-Amirkolaii *, Hedi Romdhana *(1) and Marie-Laure Lameloise \\ AgroParisTech, UMR1145 Ingénierie Procédés Aliments, 1 av. des Olympiades, F-91300 Massy, France \\ * Correspondence: keivan.nemati-amirkolaii@agroparistech.fr (K.N.-A.); \\ hedi.romdhana@agroparistech.fr (H.R.)
}

Received: 19 June 2019; Accepted: 15 August 2019; Published: 19 August 2019

\begin{abstract}
The implementation of sustainable water management practices, through the recycling and reuse of water, is essential in terms of minimizing production costs and the environmental impact of the food industry. This problem goes beyond the classical audit and housekeeping practices through developing a systemic water-using reduction strategy. The implementation of such an approach needs R\&D development, especially for the food industry, where there is a lack of knowledge on: (a) process integration and (b) data on the pollutant indicators or (c) volumes of water used and discharged at specific steps of the food processing line. Since energy pinch analysis emerged, different variations of pinch methods have been developed. As a variation of pinch, Water pinch analysis is a global and systematic approach to minimize water consumption and discharges, especially for the most energy-intensive and water-consuming factories. Based on the nature of the food industry, the real systems are complex, multi-source multi-contaminant systems, the problem should be well formulated, including mathematical constraints (inequalities thresholds). Current work has reviewed comprehensive literature about different variations of pinch analysis. In continue, water pinch method deeply discussed and some relevant data concerning the water using process and pollutant indicators have been reviewed with emphasis on the food industry sector.
\end{abstract}

Keywords: process integration; pinch analysis; food industry; water

\section{Introduction}

Setting energy targets is the first fundamental concept of pinch analysis [1]. This approach is based on the optimization of resources and tries to allocate limited sources to the demands in the best way. Based on this definition, the method has been developed for different applications, especially for minimizing water consumption. Further developments have resulted in methods for minimizing water use and various industrial utilities like hydrogen, oxygen, etc.

Water pinch is a global and systematic approach to minimize freshwater and wastewater, especially for the most energy-intensive and water-consuming factories. Wang and Smith [2] showed that mass pinch analysis appears as a particular case of mass integration, especially to minimize the consumption of water or any other fluid. Later, a systematic approach was developed to optimize water networks of the industrial site by applying analogy with thermal pinch analysis [3,4]. This approach provides results just as spectacular as energy analysis to optimize water consumption. Almató et al. [5] identified potential water savings of $63-72 \%$ in a fruit juice production industry. The work of Thevendiraraj et al. [6] and Tokos and Novak Pintarič [7] identified potential water savings of 30\% respectively in a brewery workshop and a citrus juice production workshop. Recently, the parallel application of water pinch and mathematical optimization considered as well, which find a water savings of $30 \%$ in a corn refinery [8]. 
In the food industry, energy efficiency has become more than ever a priority to improve the environmental and economic performance of industrial sites. The environmental and economic regulations impose a variety of measures in the food industry. Water resources must be saved as much as possible, especially for certain regions where water is becoming increasingly scarce because of climatic hazards due to human activities and the denaturation of freshwater sources. On the other hand, the new regulations require more constraints to reduce and/or optimize the discharges loaded with organics like carbon, nitrogen, phosphorus, acid, etc. The new European rules aim for zero discharges into polluted water (2455/2001/EC and 2000/60/EC). Faced with these increasingly serious issues, the food industry has to go beyond simple measures (best practices) and employ more efficient methods. The integration of high-performance equipment for water purification is strongly recommended by the European IPPC Directive (96/61/EC). However, the annual cost of these techniques can amount to 2.5-3.5 million euros [9]. It is therefore essential to identify the possibilities of minimizing the consumption of water and the polluting load before integrating the purification equipment by using mass integration tools.

Despite the development of Pinch Mass Analysis in many studies, this technique still occupies a small place in the industry, particularly in the food sector. As mentioned before, different variations of pinch have been developed after emerge of energy pinch concept. In this work, all different variations of pinch method have been reviewed with the main focus on water pinch analysis. In the following sections, at first different pinch methods like energy pinch analysis, $\mathrm{CO}_{2}$ emission targeting, hydrogen pinch analysis have been explained in detail by using practical examples to make a clear vision of their functions and in the next sections, some explanation about new variations of pinch like oxygen pinch analysis, emergy pinch, budget-time-income have been explained. As an important part of this study, the main focus was on water pinch analyses, so a comprehensive section about this method presented. In this section, different articles in this area of research have been reviewed and practical examples of water pinch explained as well. At the end, utilization of water pinch analysis in food industry presented. Some difficulties are due to the diversity of uses of water in the food industry, the constraints related to the quality of the water used and the various substances released. The different aspects of view like economic issue have been considered.

\section{Key Concept of Pinch Analysis}

The challenges of developing the pinch method for the optimization of primary resources (e.g., energy, water, raw material), are significant and involve intensive efforts in many application areas. The purpose of this subsection is to summarize the main research and the significant results in the area of pinch analysis.

Regarding literature, pinch analysis was initially developed for heat integration [1]. By analogy with the thermal pinch, further applications are developed in various fields, especially, mass integration [2], design and management of hydrogen networks [10], minimization of oxygen consumption of the microorganisms used for waste degradation [11], emergy analysis [12,13], $\mathrm{CO}_{2}$ emission targeting [14,15], and supply chain management [16]. Development in energy integration, territorial energy plan and hydrogen network management are addressed in detail. Further development for emergy, oxygen pinch and chain management are shortly mentioned. At the end, as the main review, the mass integration (water pinch) addressed in detail and discussed different aspects of this approach in different kind of food industries like brewing, sugar and citrus.

\subsection{Energy Pinch Analysis}

Energy pinch analysis was developed to optimize heat exchanger networks HENs. Linnhoff and Hindmarsh [17] developed the basic principle of minimization of energy utilities by optimizing the coupling between hot and cold streams. El-Halwagi and Manousiouthakis [18] were succeeded to identify a useful analogy between the synthesis of two networks of HENs and mass exchanger network (MENs) that are heat exchanger and mass exchanger networks, respectively. The authors 
explored a novel algorithm-based procedure to synthesize the MENs automatically. It was formulated based on mixed-integer linear programming (MILP). In turn, MILP generated MENs that characterized the minimum number of heat exchangers, exposed to the least amount of mass separating agents (MSA) costs. The lean stream utilized in a unit operation such as a distillation column or liquid extraction is entitled MSA. Targeting the minimum number of units does not fundamentally cause the least cost. This statement results from the graphical technique reported by Hallale and Fraser [19]. Based on the minimum number of trays, this technique was then examined as a new route for capital cost targeting for MENs. In order to obtain the closely approached targets, a new design method was also developed $[19,20]$. In recent years, different methods have been developed to improve the HEN efficiency. One of the widely discussed subjects is about HEN network retrofitting. Different methods like retrofitting without considering additional heat transfer area [21], area ratio approach [22], cost-effective strategy [23], intensified heat transfer [24] and retrofitting with fix structure [25] have been applied to improve these networks function. A new graphical method is also developed by Gadalla [26] to handle both energy integration and network retrofitting. To handle both continues and discrete variables simultaneously in HEN retrofitting and also increase the efficiency of calculation IDE (integrated differential evolution) method developed [27].

Using the targets inferred from pinch analysis, the proper designs in the view of thermal efficiency was achievable. The retrofitting of network structure is required by the relocation of an existing heat exchanger to a new duty or addition of a new exchanger or change of the stream. Composite curves were constructed from hot and cold stream data at which the targeting was acquired. Consequently, the graphical representation of the mass and heat balance of the system is presented through plotting temperature versus enthalpy of the process streams. While the minimum hot and cold utility targets are acquired, the pinch point is discovered when the two composite curves are fitted together. To illustrate the energy pinch procedure, hypothetical data was gathered in Table 1 with a set of hot and cold streams. Each stream is characterized in term of supply temperature $T_{s}$, target temperature $T_{t}$ and heat capacity flowrate $\mathrm{CP}$, assumed to be constant (Equation (1)):

$$
\mathrm{CP}(\mathrm{kW} / \mathrm{K})=\dot{\mathrm{m}}(\mathrm{kg} / \mathrm{s}) \times\left\{\begin{array}{c}
\mathrm{C}_{\mathrm{p}}\{\mathrm{kJ} / \mathrm{kg} / \mathrm{K} \text { for stream requiring heating or cooling } \\
\frac{\Delta \mathrm{H}\{\mathrm{kJ} / \mathrm{kg}}{1 \mathrm{~K}} \text { for phase }- \text { changing stream }
\end{array}\right.
$$

Table 1. Data set for energy pinch analysis.

\begin{tabular}{cccccccc}
\hline & \multicolumn{3}{c}{ Hot Streams } & \multicolumn{4}{c}{ Cold Streams } \\
\hline & $\boldsymbol{T}_{\boldsymbol{s}}\left({ }^{\circ} \mathbf{C}\right)$ & $\boldsymbol{T}_{\boldsymbol{t}}\left({ }^{\circ} \mathbf{C}\right)$ & $\boldsymbol{C P}\left(\mathbf{k W} /{ }^{\circ} \mathbf{C}\right)$ & & $\boldsymbol{T}_{\boldsymbol{s}}\left({ }^{\circ} \mathbf{C}\right)$ & $\boldsymbol{T}_{\boldsymbol{t}}\left({ }^{\circ} \mathbf{C}\right)$ & $\boldsymbol{C P}\left(\mathbf{k W} /{ }^{\circ} \mathbf{C}\right)$ \\
\hline $\boldsymbol{H}_{\mathbf{1}}$ & 200 & 100 & 20 & $\boldsymbol{C}_{\mathbf{1}}$ & 80 & 120 & 80 \\
$\boldsymbol{H}_{\mathbf{2}}$ & 150 & 60 & 40 & $\boldsymbol{C}_{\mathbf{2}}$ & 50 & 220 & 15 \\
\hline
\end{tabular}

With, $\dot{m}$ is the mass flow rate, $C_{p}$ is the specific heat and $\Delta \mathrm{H}$ is the latent heat of phase change (i.e., condensing or boiling). To visualize the heat exchange of each stream, a temperature-enthalpy diagram can be used. The individual representations of hot and cold streams are shown in Figures 1 and 2, respectively. Since the arbitrary choice of the enthalpy reference, a given stream can be plotted anywhere in the enthalpy axis. The streams are initially drawn by selecting enthalpy references at $60{ }^{\circ} \mathrm{C}$ and $50{ }^{\circ} \mathrm{C}$, respectively for hot and cold streams. To provide useful information about the energy coupling between the hot and cold streams, a single composite of all hot streams and a single composite of all cold streams can be plotted in the temperature-enthalpy diagram, and handled in just the same way as two streams. To draw the composite curve, the streams existing over any given temperature range are grouped by adding their heat capacity flowrates. The composite curves are shown in Figure 3. The cold composite is shown shifted on the $x$-axis relative to the hot composite. The overlap between the composite curves represents the maximum amount of energy recovery within the process $(4850 \mathrm{~kW})$. A minimum of temperature difference $\Delta T_{\min }$ (in this case, $10^{\circ} \mathrm{C}$ ) is respected. 
Further shifting implies larger energy recovery and then larger heat exchanger. The overshoot at the bottom of the hot composite and for which no cold streams are available represents the minimum of cooling utility (750 kW external cooling). The overshoot at the top of the cold composite and for which no hot streams are available represents the minimum of heating utility ( $900 \mathrm{~kW}$ external heating). The selection of the minimum temperature difference is of great practical importance. Generally, the higher values of $\Delta T_{\min }$ give higher hot and cold utility requirements and inversely. Therefore, targeting procedure is essential to identify the most economical ways of maximizing heat recovery and of minimizing the demand for external utilities.

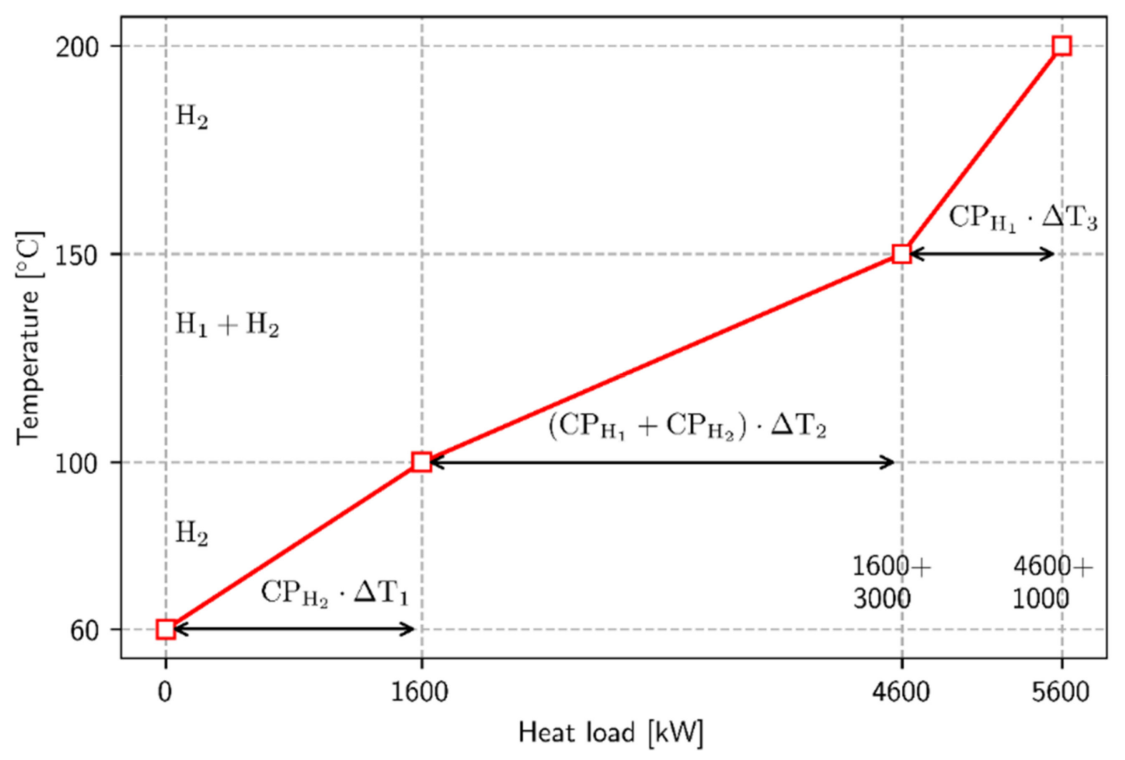

Figure 1. Hot composite curve.

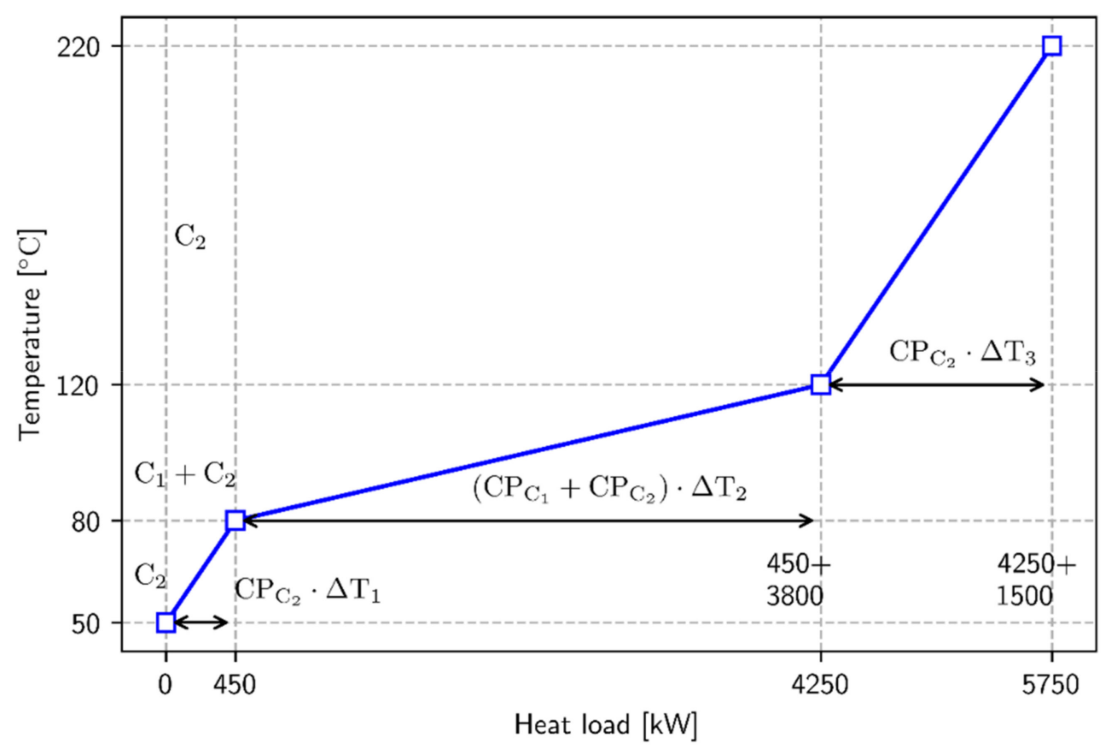

Figure 2. Cold composite curve. 


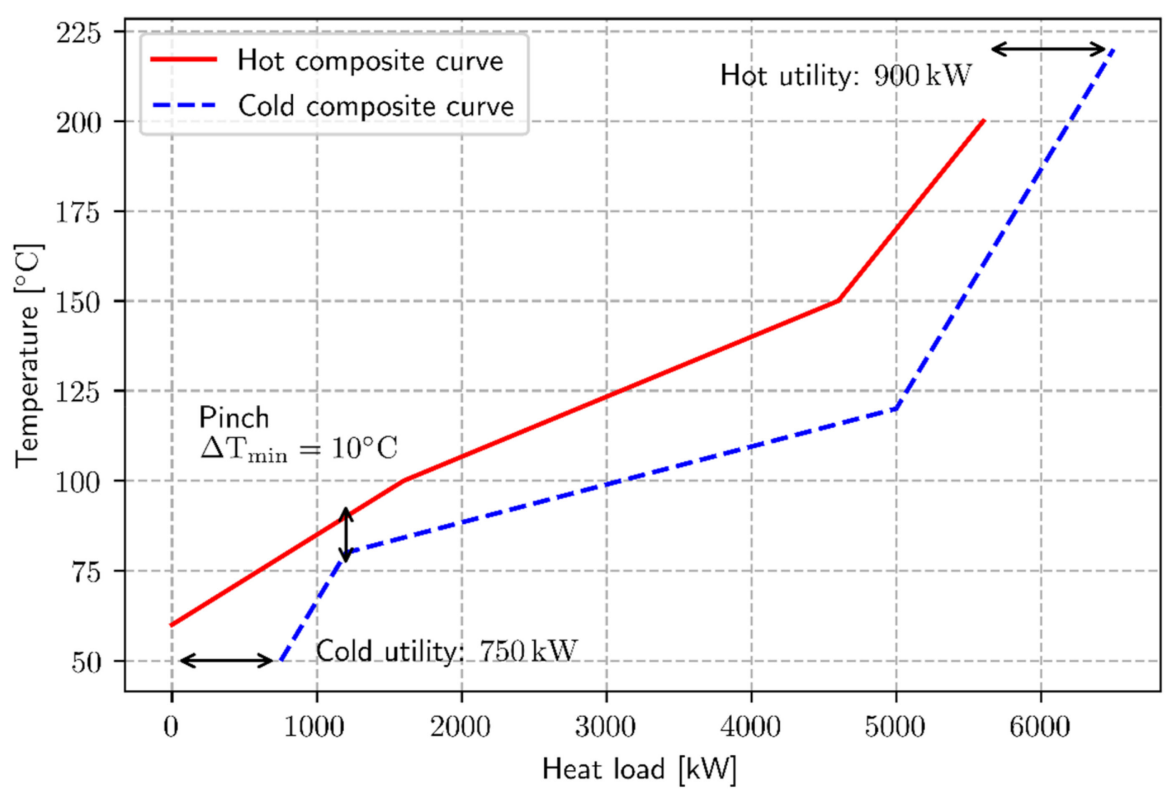

Figure 3. Balanced composite curves and energy recovery target.

\subsection{Territorial Energy Plan ( $\mathrm{CO}_{2}$ Emission Targeting)}

An economic sector is the subject of inevitable energy demand (e.g., territorial regions). In order to meet national or regional greenhouse emissions limits, energy planning is required. For this purpose, the pinch analysis can be used for determining how the energy resources should be assigned among the energy demands. After proposition of the first concept by Tan and Foo [15], different variation of this method like: mix of graphical and automated targeting approach [28], unified pinch with considering different time periods and regions [29], hybrid algebraic graphical method for carbon capture and storage (CCS) [30], Waste Management Pinch Analysis (WAMPA) [31] have been developed. In addition, it's application in different industries like Irish electricity generation sector [32] and the New Zealand electricity sector [33] have been tested. In recent years, Carbon emissions pinch method mixed with new concepts like Life cycle assessment and carbon footprint which can be useful to analyze the economic and environmental aspect of the system simultaneously [34]. To illustrate the pinch procedure, hypothetical data was reported from Tan and Foo [15] study. Table 2 shows a set of expected demand for energy in three geographical regions. Each region is subject of greenhouse gas emission quotas (allowances). In order to meet the specified emission limits, an economic sector must include energy sources with zero or near-zero $\mathrm{CO}_{2}$ emissions (e.g., nuclear, renewable energy). These energy resources must be minimized given the high economic costs (case of renewable energy) or because of the risk factors that limit public acceptability (case of nuclear energy). Pinch analysis involves minimizing the energy resources required to meet the specified emission limits.

Table 2. Inventory data for carbon-constrained energy planning (Tan and Foo 2007).

\begin{tabular}{|c|c|c|c|c|c|}
\hline \multicolumn{3}{|c|}{ Energy Resources } & \multicolumn{3}{|c|}{ Energy Demands } \\
\hline Available & ources & Emission Factor & Expected & nands & Emission Quota \\
\hline \multicolumn{2}{|c|}{ TJ } & \multirow{2}{*}{$\frac{\mathbf{t} \mathbf{C O}_{2} / \mathrm{TJ}}{105}$} & \multicolumn{2}{|c|}{ TJ } & $10^{6} \mathbf{t} \mathbf{C O}_{2}$ \\
\hline Coal & 600,000 & & Region 1 & $1,000,000$ & 20 \\
\hline Oil & 800,000 & 75 & Region 2 & 400,000 & 20 \\
\hline Natural gas & 200,000 & 55 & Region 3 & 600,000 & 60 \\
\hline Others $^{\text {a }}$ & $>400,000$ & 0 & & & \\
\hline
\end{tabular}

a energy source with zero $\mathrm{CO}_{2}$ emissions. 
From the data in Table 2, the composite curves for energy sources and demands can be plotted as shown in Figures 4 and 5, respectively. To plot the supply composite curve (i.e., source composite curve), the available sources are first arranged in order of increasing emission factors. Zero-carbon energy sources are initially excluded. The product of the available energy and the emission factor of each energy source provide the total $\mathrm{CO}_{2}$ emissions. Each energy source is plotted on the axis system: total $\mathrm{CO}_{2}$ emissions ( $y$-axis) as a function of the cumulative available energy ( $x$-axis). The slop of each source is equal to its emission factor.

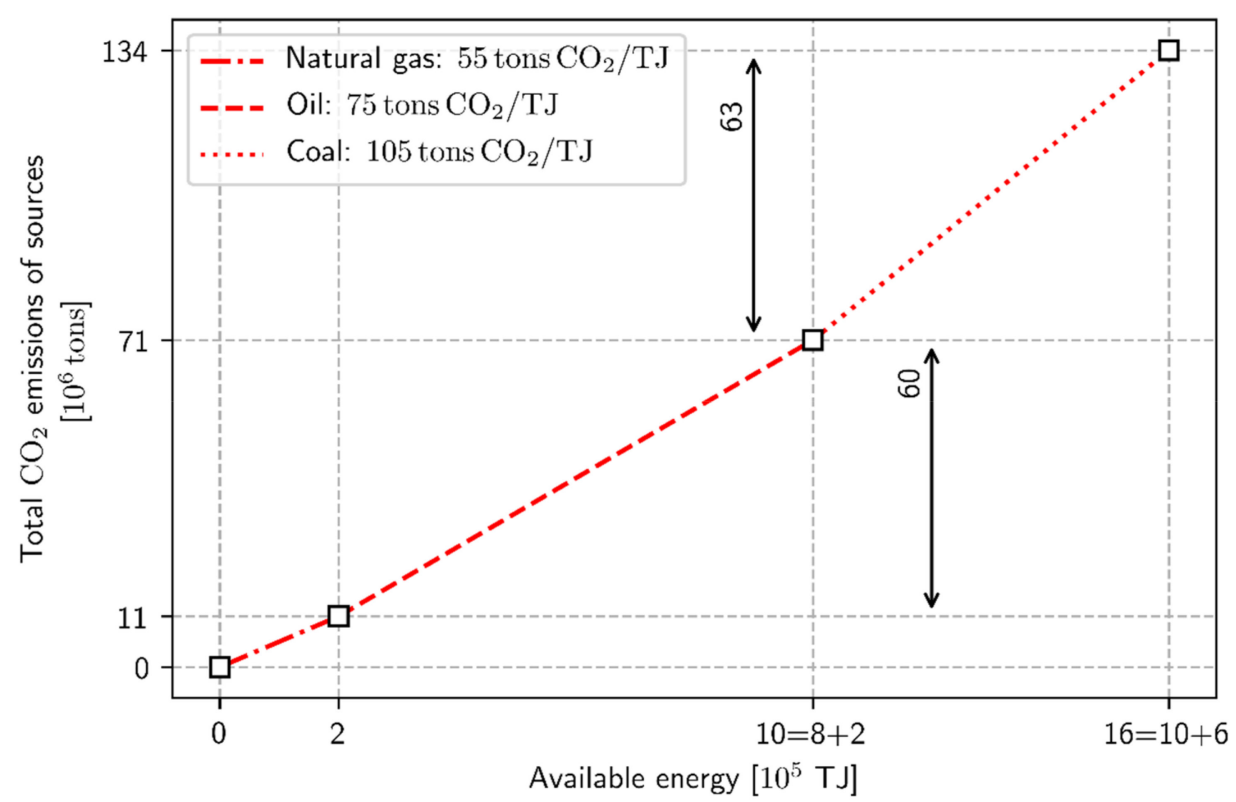

Figure 4. Energy supply composite curve.

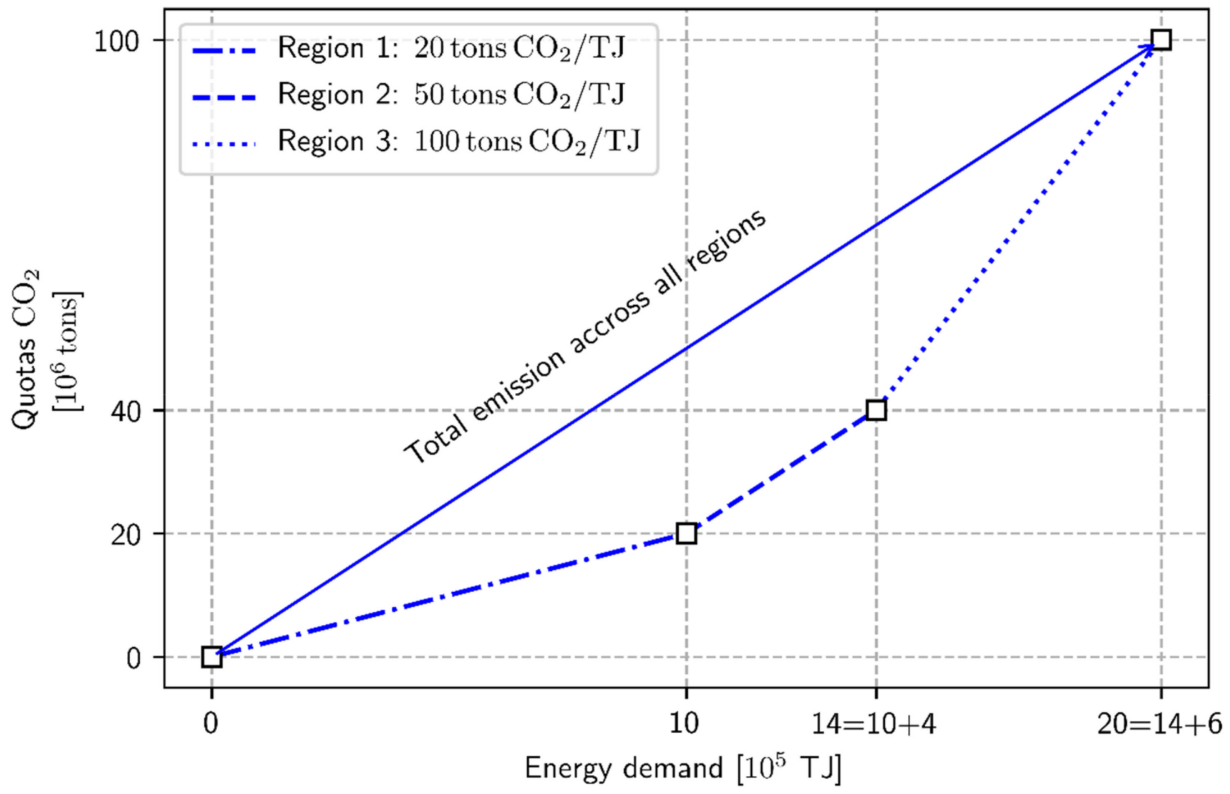

Figure 5. Energy demand composite curve.

The composite curve of energy demands is obtained similarly, with the $x$-axis representing cumulative energy demands and the $y$-axis representing the total allocated $\mathrm{CO}_{2}$ emissions (i.e., total emission quotas). Note that the three regions can be taken as a single demand without regard to their 
individual, disaggregated emission limits, resulting in the composite curve indicated by the continuous line (Figure 5).

Emission targeting via pinch analysis can be investigated by combining the two composite curves (Figure 6). In order to provide the required energy sources, the source composite curve is shifted horizontally to the right, until the two curves touch each other at the pinch point. The horizontal distance between the origin and the composite source line represents the amount of zero-carbon energy required for the economic system, in this case approximately $7.2 \times 10^{5} \mathrm{~T}$.

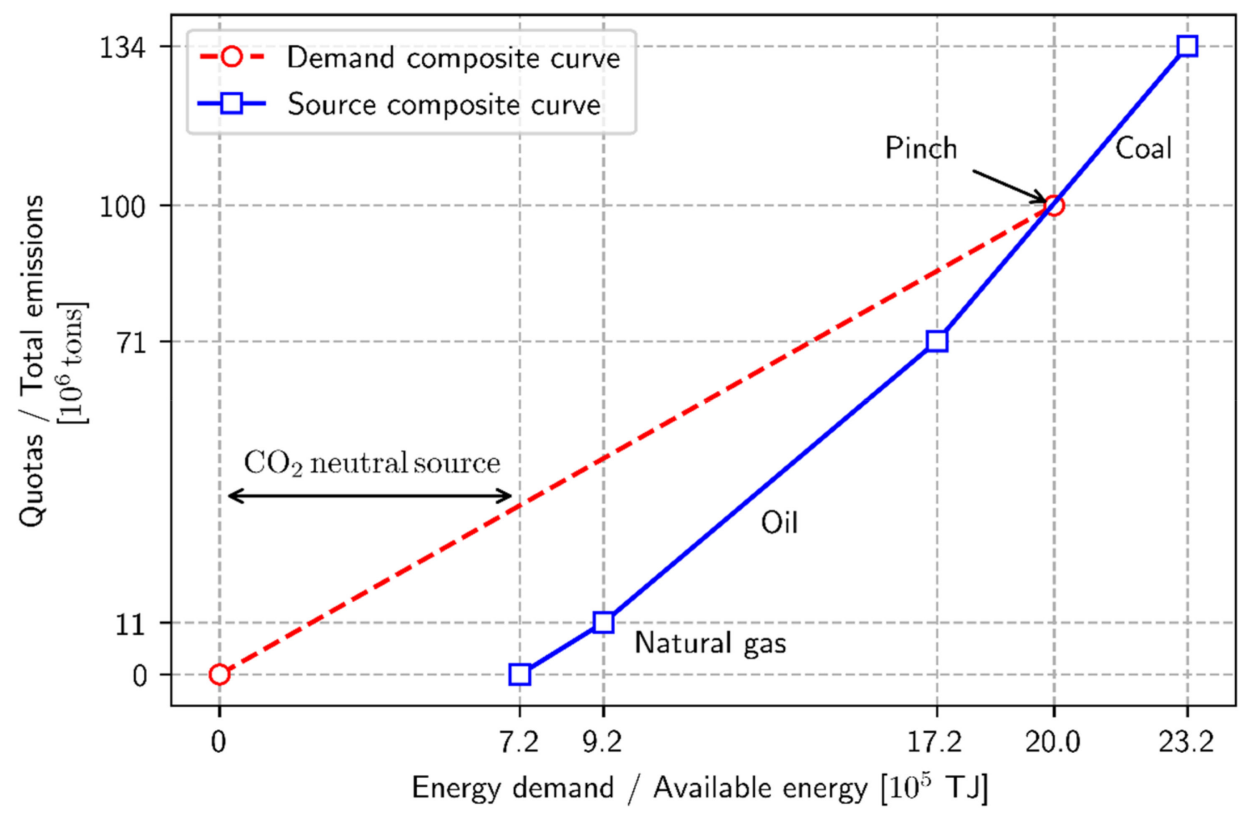

Figure 6. Targeting demand for $\mathrm{CO}_{2}$ neutral energy.

\subsection{Design of Hydrogen Networks}

Hydrogen networks play an important role in refineries and large amounts of hydrogen are used for fuel production. Hydrogen networks involve consuming (sink), producing (source) hydrogen operations [35]. The management of the hydrogen network can be performed through pinch analysis by providing a good understanding of the mass balance of sink and source units and the system limitations. Further developments of hydrogen pinch belongs to add some details like pressure constraint [36], demand uncertainty [37] and test the different solving approaches, like solving the MINLP model with different mathematical formulation to improve the accuracy of answers [38-40]. Recently, Hydrogen network design based on mathematical modeling and also considering reuse and recycle proposed by Deng et al. [40]. To illustrate the pinch procedure, hypothetical data was reported from Alves and Towler study [41]. Table 3 shows a set of sinks and sources of a fictive hydrogen network:

Table 3. Inventory data of sinks and sources of a fictive hydrogen network [41].

\begin{tabular}{cccc}
\hline \multicolumn{2}{c}{ Sinks } & \multicolumn{3}{c}{ Sources } \\
\hline Flow Rate $\left(\mathbf{N m}^{3} / \mathbf{h}\right)$ & $\boldsymbol{H}_{2}$ Purity (\%) & Flow Rate $\left(\mathbf{N m}^{3} / \mathbf{h}\right)$ & $\boldsymbol{H}_{2}$ Purity (\%) \\
\hline 2495.0 & 80.6 & 350.0 & 95.0 \\
180.2 & 78.9 & 623.8 & 93.0 \\
554.4 & 77.6 & 415.8 & 80.0 \\
720.7 & 75.1 & 1940.5 & 75.0 \\
& & 346.5 & 73.0 \\
& & 457.4 & 70.0 \\
\hline
\end{tabular}


The mass balance of each source and sink can be represented through a two-dimensional plot of total gas flow rate versus hydrogen purity. Figure 7 shows the composite curves of sinks (dashed line) and sources (solid line). The two composites profiles start at a zero flow rate, with a horizontal line determined by the flow rate of the specific source or sink. The next source or sink in the order of purity is then plotted in the diagram, also as a horizontal line. Once again, the length will be determined by the flow rate of the specified source or sink, which start at the same gas flow rate as were the previous source or sink ended. This is repeated until all sources and sinks are presented in the diagram. The area above the sink profile and below the source profile indicates the surplus where sources provide more hydrogen than is required by sinks. Vice versa, the area indicates a deficit of supply. Figure 8 allows good visualization of the hydrogen surplus by calculation the net cumulative balance between sinks and sources. The minimum of hydrogen utility can be determined by horizontally moving the curve toward purity axis until the vertical segment between sink and source touches the purity axis.

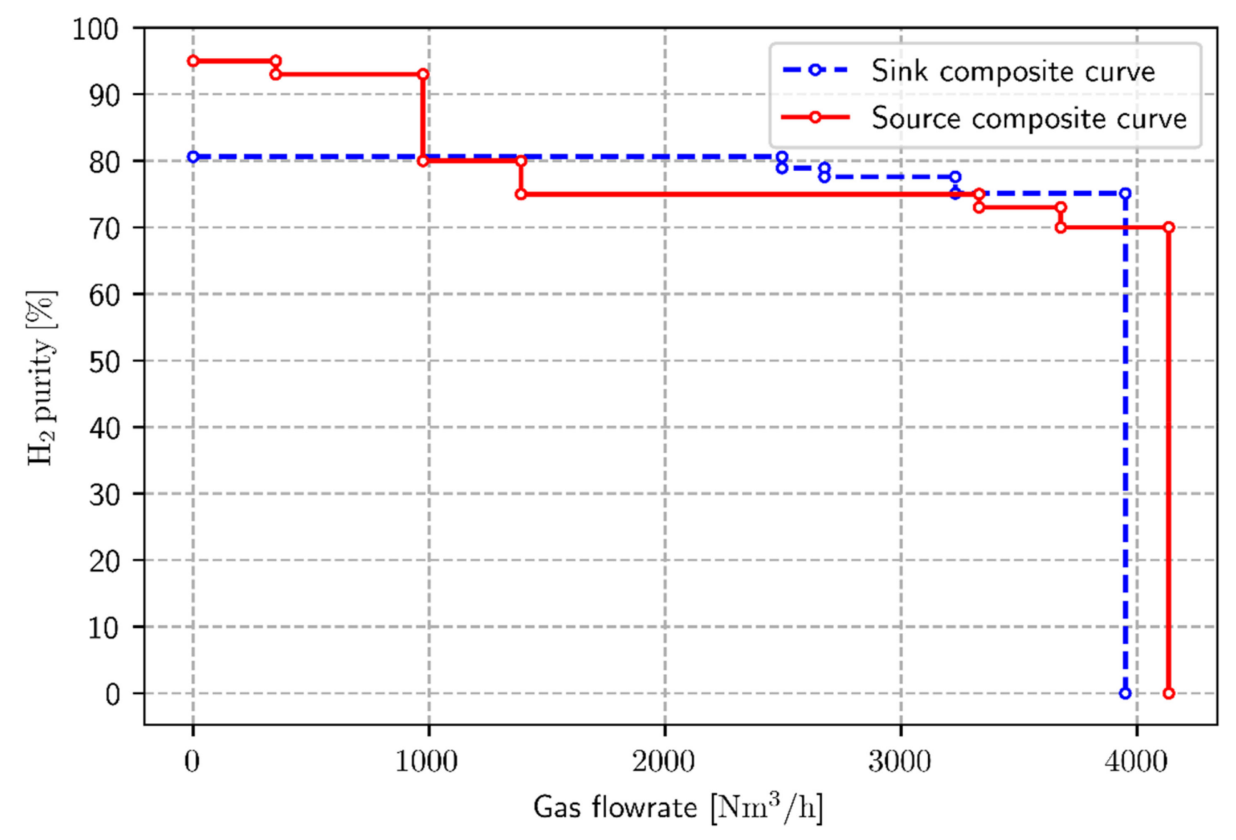

Figure 7. Composite curves of hydrogen network.

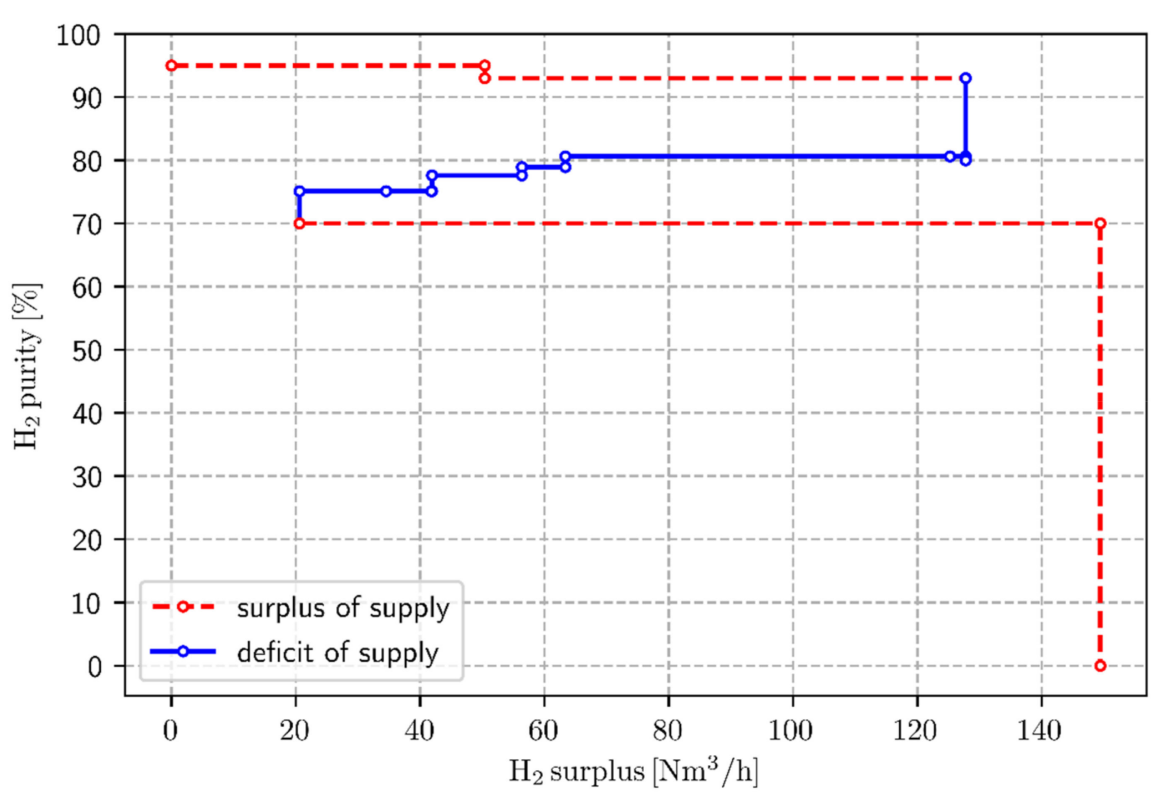

Figure 8. Hydrogen surplus diagram. 


\subsection{Oxygen Pinch Analysis}

In a wastewater treatment plant, the oxygen is essential for the oxidation reactions of carbon and nitrogen pollution (removal of COD and nitrification). To improve energy performance, it is essential to minimize the supply of oxygen, which is a very energy-intensive operation. For this purpose, oxygen pinch analysis has been developed by Zhelev and Ntlhakana [11]. This method aims to help with designing the wastewater treatment systems with cost efficiency. The method consists first in establishing composite curves using water pinch analysis. The curves are established individually by drawing concentration of COD as a function of the mass flowrate of COD. After that, all the streams are aggregated within a resulting composite curve. The oxygen required is then calculated by plotting line between the origin and the pinch point. The inverse of the slope of the limiting oxygen line is the flow rate of the required oxygen [11]. With the implementation of the new method, about 30 percent decrease in costs of wastewater treatment plant has been obtained [42]. Mass pinch transfer concept is the heart of oxygen pinch analysis but potentially oxygen pinch oversteps the targets of the classical pinch. There are some quantitative and qualitative targets within oxygen pinch. The quantitative targets like oxidation energy load, residence time, oxygen solubility and qualitative targets like growth rate that presents the micro-organisms age and health [42]. Last detailed work about this methods backs to Zhelev article [43], developed a hybrid method which named Water-Oxygen-Thermal Pinch Analysis applied to manage the treatment system of wastewater in the industry. This technique almost mixed with other pinch methods like water and not used a lot in literature.

\subsection{Emergy Pinch}

Emergy is the solar energy that is available for utilization directly or indirectly to produce a product or service [12]. Emergy was used as an environmental indicator to perform life cycle assessment of different ecosystems goods and services, e.g., human labor, trucks [44]. Emergy can be used in energy pinch analysis as cost criteria. The objective is to provide an economic capturing human demand and values to the analysis [45]. In Hau and Bakshi's work [46], challenges and problems of emergy pinch considered in detail. In addition, the relation between emergy and engineering concepts like exergy has been discovered. Zhelev and Ridolfi [13] tried to integrate pinch and classical emergy together and propose an integrated concept for the management of resources in a better way. In recent years, some real application of emergy in different industries like steel companies [47] and power plants [48] have been considered.

\subsection{Budget-Time-Income}

With inspiration from integrated management for different sources like steam, fresh water, electrical energy, etc. budget-time-income techniques help to increase profits and decrease investment costs. It's possible to use the pinch principles for amalgamation of finances in the resources management sector. Like other classical pinch methods, in this method, the cost composite curve has also been developed to help for targeting the optimal profitability. This helps the experts for trade-offs and decision-making. To do the targeting for combined resources, cost composites (combined composites in classic methods) has been developed as curves of all resource like water, energy, etc. Based on water pinch analysis diagram, a plot has been developed to present the flowrate of money to guaranty the meet of targets. This method makes the vital amalgamation between businesses and industrial resources management. This flow diagram (money management FD) is an important tool for targets the min of repayment periods, borrowing timetables, commissioning, money management and also it would be helpful for budgeting actions, etc. [16]. This variation of pinch applied for resource allocation in stochastic problems [49] and also it's known as financial pinch analysis, which is a tool for financial aspects of projects [50], and also it can combine with mathematical modeling concept to solve more complex problems [51]. 


\subsection{Summary and Discussion}

Pinch concept is an optimization procedure to find the best tradeoff between demand and present sources. The pinch can apply for different cases even far from the scope of its first development like emergy, oxygen, hydrogen and also in some researches pinch applied to find tradeoff in Budget-time-income sector which explained in the previous section.

Within these variations, different objectives have been followed to obtain. In energy pinch goal is to understand the most possible heat exchange between different hot and cold streams. For this reason, normally some data like input and output temperature and heat capacity are required, which not hard to measure. Thanks to Linnhoff and Hindmarsh [17], different works based on real cases published and reliable results in the economic and environmental aspects presented. Other variation of pinch developed In order to meet the specified emission limits with zero or near-zero $\mathrm{CO}_{2}$ emissions [15]. This variation of Pinch analysis which called $\mathrm{CO}_{2}$ emission targeting, involves minimizing the energy resources required to meet the specified emission limits. Based on industry's needs about managing hydrogen networks, especially in refineries, hydrogen pinch developed [35]. It can be performed through pinch analysis by providing a good understanding of the mass balance of sink and source units and the system limitations. Oxygen pinch was developed by Zhelev and Ntlhakana [11] to improve the energy performance as it is necessary to minimize the supply of oxygen, which is a very energy-intensive operation. In other variations of a pinch like emergy and budget-time-income the aim is optimizing some resource. These methods were applied already to real cases and have shown good results and impressive amounts of resource savings. Collecting the required data (temperature, flowrate, measurement of chemical combinations, etc.) is not easy always and sometimes based on the real-world situation the measurements can be hard, challenging or even impossible.

Based on these experiences, it seems application of this known optimization procedure to water networks can have an impressive effect, which we will study about these details in the next sections. One of the most important applications of the pinch concept, called water pinch analysis, refers to water. The pinch concept tries to find an optimal tradeoff between different water sources (fresh, reused, recycled, etc.) and water demands in different industrial sectors. The concept of energy pinch has been explained before and water pinch will explain comprehensively in Section 2. Firstly, an introduction about water pinch is presented and after the literature on water pinch is reviewed and finally, an example of mono-contaminant water pinch analyses based on Wang and Smith [2] has been presented to make this method more understandable.

\section{Water Pinch Analysis}

The first version of the pinch method proposed by Linnhoff [52] was called energy pinch analysis and after that different pinch variations have been developed. One of these variations is named process mass integration pinch. This method aims to design a global and systematic approach for minimizing water consumption and discharges, especially for the most water-consuming and energy-intensive factories. Wang and Smith [2] first applied this method to water and named it water pinch analyses. After that, different researchers have tried to improve the efficiency of this method by developing new variations of water pinch or proposing new approaches. For example El-Halwagi, Gabriel, and Harell [3] and Prakash and Shenoy [4] obtained good results concerning water consumption reduction with using water pinch analysis. There are also different works with the same point of view but focusing on food industries (juice, brewery and corn refinery) [5-7].

In the following section, we mainly focus on different aspects of water pinch analysis. First, the history of different developments of water pinch have been reviewed to know more about the details. After, to present the water pinch procedure for a mono-contaminant water system, the data of Wang and Smith [2] has been considered. 


\subsection{History of Water Pinch Development}

Superstructures were presented using the concept of the general system structures [53]. They looked at the reduction of water level within the whole system of water-using and wastewater-treatment units. In the total system, optimizing water allocation was considered as an issue for maximizing the water reusability. Programming based on mathematical approaches was utilized, as it allows transforming the problem into a series of sub-problems. Elimination of the initial problem of searching for attainable points was done employing a penalty function without imbalance limitations. This work set the stage for the application of pinch technology to minimizing the water and wastewater treatments either through graphical or numerical methods.

In order to minimize the wastewater used for water re-use, a graphical method based on the concept of the constraining composite curve and minimum water supply line was reported by Wang and Smith $[2,54]$ to target and design the regeneration re-use and regeneration recycling. This method also searches the multi-contaminant processes. The following work of Wang and Smith [55] was later expanded to processes that required a fixed flowrate, processes with water losses and multiple sources of freshwater. The design method proposed includes complex breaking loops in the design network [56].

To bring the difficulty of loop breaking under control, a new design procedure was introduced by Olesen and Polley [57] continuing the work of Wang and Smith [2] for single contaminant problems. Also, to make the previous design methods more comprehensible a new graphical approach was explored $[58,59]$. This new methodology results in better constructions for regeneration re-use and recycle designs.

Distributed effluent treatment systems were designed by Wang and Smith [54]. They aimed to minimize cost by keeping the flow treated to a minimum. Comparable in certain respects to the developed method by [2], they fitted an effluent treatment line based on an effluent composite curve to find the minimum treatment volume target. They presented design rules for the achievable treatment target and developed a method for designing a distributed effluent network. The method was also extended to multiple contaminant systems. The distributed effluent treatment design was first reported by Wang and Smith [54] and further expanded by Wen-Chu Janice Kuo and Smith [60]. They also handled a superstructure and mathematical techniques in order to find a solution for multi-contaminant issues. However, the superstructure is simplified with the deep intuitive understanding using graphical targeting.

The methods introduced by Wang and Smith $[2,54,55]$ were then re-worked by Castro et al. [61] and the concept of multiple pinches was created. This filtered the design of networks that do not lead to the treatment systems with the minimum-cost distributed effluent.

Furthermore, the concept of the two composite plots was introduced by Dhole et al. [62], which plotted the water sources and water demands with the purity on the y-axis and flow on the x-axis. This useful way to utilize the plot to find freshwater and wastewater targets were explained, as well as the network design. Water pinch, the name of this process, was combined with numerical techniques to solve the problem.

Hallale [63] reassessed the method of Dhole et al. [62] and paid particular attention to the equivalency of two-composite plot representations and the true reflection of the target because both the shape of the source composite plot and the targets can be altered by mixing of water sources. The two-composite plot is consequently not an accurate targeting approach, but rather a graphical representation of the particular design that has been acquired using mathematical programming.

The concept of a Water Surplus Diagram was introduced by Hallale [63] as an alternative targeting approach to that previously presented by Dhole et al. [62]. For this targeting method, a design procedure was also developed. It was mentioned that it is probable to use mathematical programming techniques for solving multiple-contaminant problems [63]. Linear (LP) and non-linear (NLP) mathematical formulations for targeting the re-use of water with multiple contaminants [64]. It was able to dominate the difficulty of non-linear programming by combining the LP and NLP approaches. They suggested 
that the NLP problem can be solved using a solution for the linear model and provide the initial values for the NLP optimization.

Doyle and Smith [64] and Alva-Argáez et al. [65], reported a developed and automated method for the synthesis of industrial systems for water regeneration. Through this method, the maximum outlet concentrations were chosen and the treatment unit concentrations were set to zero. Both the sum of the model errors in the objective function and capital and the operating cost were considered in the design. That is, running the linear program will reduce the error to zero. The series of linear optimizations will consequently converge to the NLP solution.

A mathematical model was developed and utilized for distributed wastewater networks [66]. Rather than discovering a global optimum that leads to convergence difficulties, this model is able to identify local optima for a non-linear, non-convex obstacle. A search procedure was then proposed involving the sequential global or near-global optimum solutions within a relaxed linear model (MILP) and a non-linear model (MINLP). In order to set up and solve the MILP and MINLP models, GAMS is utilized throughout the approach. Ching-Huei Huang et al. [67], followed the similar NLP procedure for determining the capacity of wastewater treatment and the freshwater consumption at the minimum contents. Synthesizing the resulting water usage and treatment network, the method is a good candidate. The MILP method for rapid screening of designs was developed by to minimize the total operational and investment costs, even where the contaminant concentration is probably not available. When data are limited, this approach can be used, however, the well-known system and its limits should be available [68].

Assessing the economic performance of industrial wastewater reuse systems, Feng and Chu [69] presented a methodology for wastewater treatment. Compared to the cost of wastewater regeneration and reuse, the saving costs of freshwater and wastewater disposal need to be balanced. Pinch analysis applied to water makes it possible to identify projects leading to a minimal use of water in the overall plant and the minimization of liquid effluents. Economically, it is interesting to reduce the investments required to increase the plant production rate by saving water and by reducing the effluent to be treated. Such analysis can be applied to the most processes in the agro-food industries including high consumption of water and production of wastewater.

The use of new numerical techniques like water cascade analysis (WCA) instead of graphical approaches like water surplus diagrams has been proposed by Manan et al. [70], who find impressive savings (up to $40 \%$ for freshwater and $30 \%$ for wastewater with considering reuse and up to $60 \%$ for freshwater and $40 \%$ for wastewater with considering reuse and regeneration) as results. In another work of Tan et al. [71], they focused on proposing a new technique to retrofit and redesign water networks based on water pinch analysis. They consider the possible regeneration in these water networks.

The applications of water pinch in oil refineries are impressive too. Considering a multi-contaminant system in oil refineries water savings reaching up to 15\% [72]. Considering recycling, reuse and regeneration is another point of their work. In the same area of research, Mughees and Al-Ahmad (2015) proposed a tool based on water pinch analysis for a refinery in Tehran. They found almost $40 \%$ water savings by considering a multi-contaminant system and tested both graphical and mathematical tools.

Based on two comprehensive review papers [56,73], in recent years the application of the mathematical models mixed with the water pinch concept for managing water networks has grown. Boix et al. [73], proposed a mathematical model to handle multi-contaminant systems, with a solving procedure based on Multiple Criteria Decision Making (MCDM) methods for MINLP models. Later, De-León Almaraz et al. [74] completed the previous work by considering more details and complete databases. These two works [73,74] led to the development of an extensive water network allocation network for a different type of industries by handling multi-contaminant systems. In the oil refinery sector mathematical models have been developed as well $[72,75]$ to handle multi-contaminant systems while considering regeneration, reuse and recycling, and good reductions in water consumption are also found by applying this method. Some studies have focused on reuse opportunities [76], some on 
the regeneration process [77] and some others on regeneration and recycling together [78], and after they proposed their MINLP mathematical model to manage water networks in different sectors like the dairy and chemical industry, etc.

Recently, Skouteris et al. [79], performed research in the brick-manufacturing industry. To manage water systems in this industry, they used two techniques which they named water pinch analysis and water footprint. The results demonstrate that using an integrated tool based on these two methods improves the efficiency of the water management system.

Based on the energy pinch definitions and according to the flexibility of this method to be applied in different cases like water, oxygen, etc. it's necessary to find the analogies of each element in new variations of pinch to apply this method. There are some analogies between energy and water pinch which are presented in Table 4; these analogies help us to apply this method in the water sector. For example, heat exchanger network design is equal to water network design in water pinch and heat capacity flowrate is equal to the water flow rate in the water pinch method and the definition of the hot and cold stream in energy pinch can be compared with the sink and source concept in water pinch techniques.

Table 4. Analogies between process heat and mass integration.

\begin{tabular}{cc}
\hline Heat Transfer-Based (Energy Pinch) & Mass Transfer-Based (Water Pinch) \\
\hline Heat Exchanger network design & Water network design \\
Temperature & Purity of water \\
Heat capacity flowrate & Water flowrate \\
Heat flow & Pollutant flowrate \\
Cold stream & Sink water \\
Hot stream & Source water \\
Heat-Pump & Purification Unit (Regeneration) \\
\hline
\end{tabular}

\subsection{Method Description}

To illustrate the water pinch procedure for a mono-contaminant water system, hypothetical data were reported [2]. Table 5 shows the inventory data of a water-using operation.

Table 5. Data set for water pinch analysis [2].

\begin{tabular}{cccc}
\hline \multirow{2}{*}{ Unit } & \multicolumn{3}{c}{ Pollutant Threshold } \\
\cline { 2 - 4 } & $C_{\text {in }}(\mathbf{p p m})$ & $\boldsymbol{C}_{\text {out }}(\mathbf{p p m})$ & $\dot{\boldsymbol{m}}_{\boldsymbol{w}}(\mathbf{t} / \mathbf{h})$ \\
\hline $\mathrm{U} 1$ & 0 & 100 & 20 \\
$\mathrm{U} 2$ & 50 & 100 & 100 \\
$\mathrm{U} 3$ & 50 & 800 & 40 \\
$\mathrm{U} 4$ & 400 & 800 & 10 \\
\hline
\end{tabular}

The inventory includes water mass flow rate $\dot{m}_{w}$ and the pollutant threshold at the input and the output of each unit operation $\left(C_{\text {out }}\right.$ and $\left.C_{i n}\right)$. The first step consists of establishing a global water demand of all units (called composite curve demand). Figure 9 shows the individual demand line of each unit. The demand is represented in a two-dimensional plot: water purity ( $y$-axis) versus pollutant mass flow rate ( $x$-axis). The mass flow rate of pollutant $\dot{m}_{C}$ is the product of the supplied water and the water purity difference between the input and output of each unit (Equation (2)):

$$
\dot{m}_{C}=\dot{m}_{w} \cdot\left(C_{o u t}-C_{i n}\right)
$$




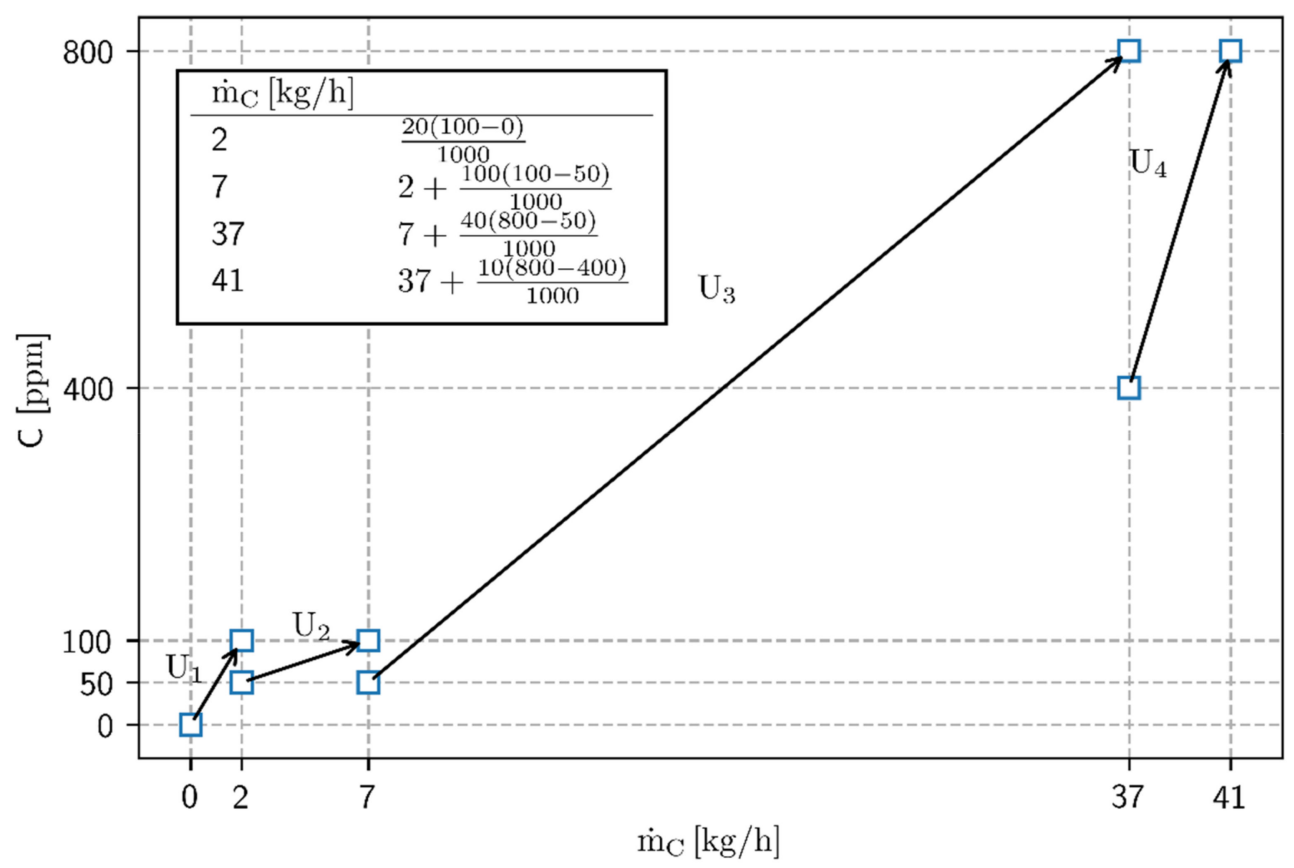

Figure 9. Limiting water profiles for each unit.

In order to establish the composite curve, the individual demands of units of the same purity-interval are accumulated. The result of the procedure is presented in Figure 10. According to Figure 11, the minimum water supply can be obtained by drawing the first intersection with the demand line ( $90 \mathrm{t} / \mathrm{h}$ of water at $0 \mathrm{ppm}$ ). This first water resource will be used to ensure the transfer of $9 \mathrm{~kg} / \mathrm{h}$ of pollutants. To transfer the remaining pollutants (up to $41 \mathrm{~kg} / \mathrm{h}$ ), a second source of water is required. The second water source is obtained by recycling the available water. Similar to freshwater, the recycling can be deduced by drawing the second intersection with the demand curve $(45.7 \mathrm{t} / \mathrm{h}$ of wastewater at $100 \mathrm{ppm})$.

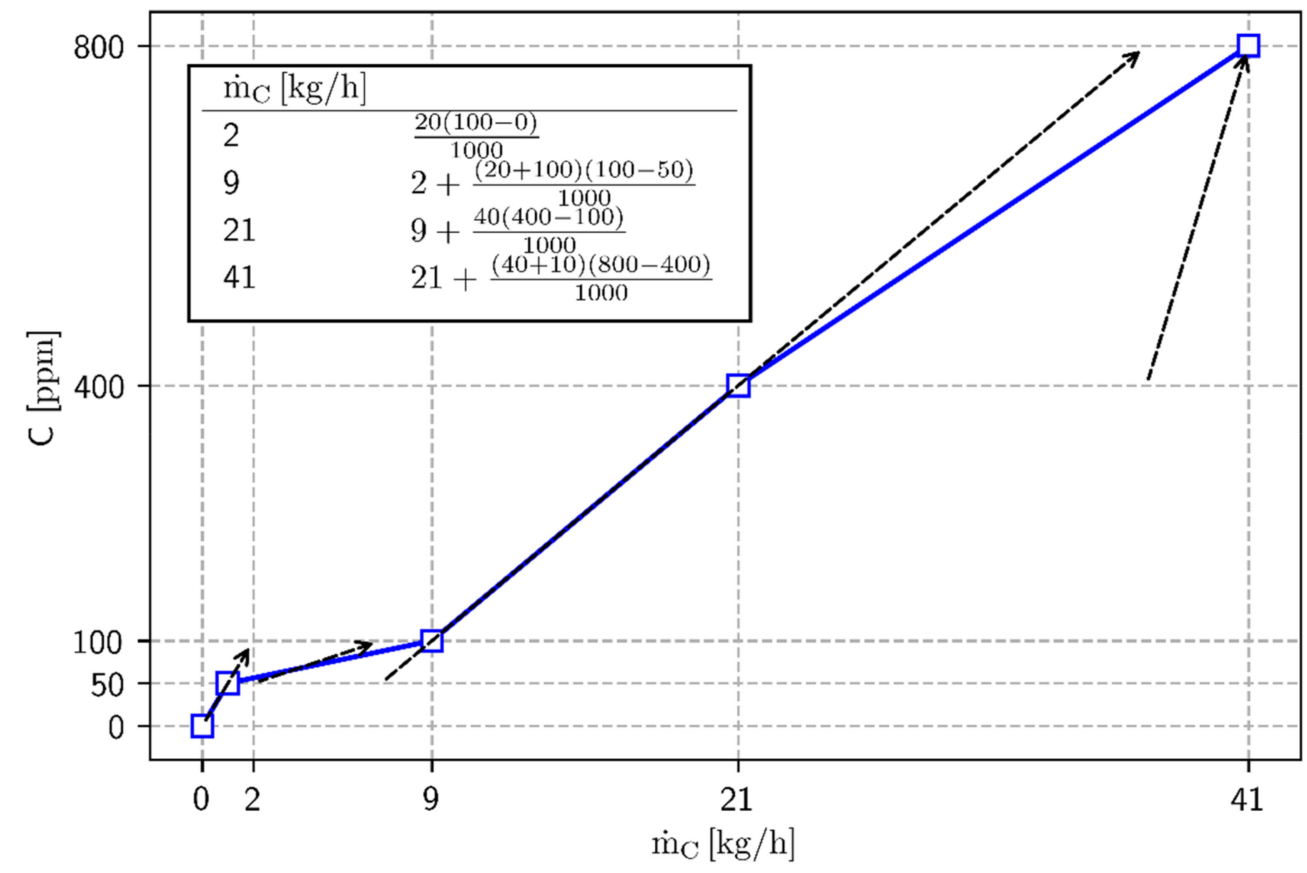

Figure 10. Composite line of water demand. 


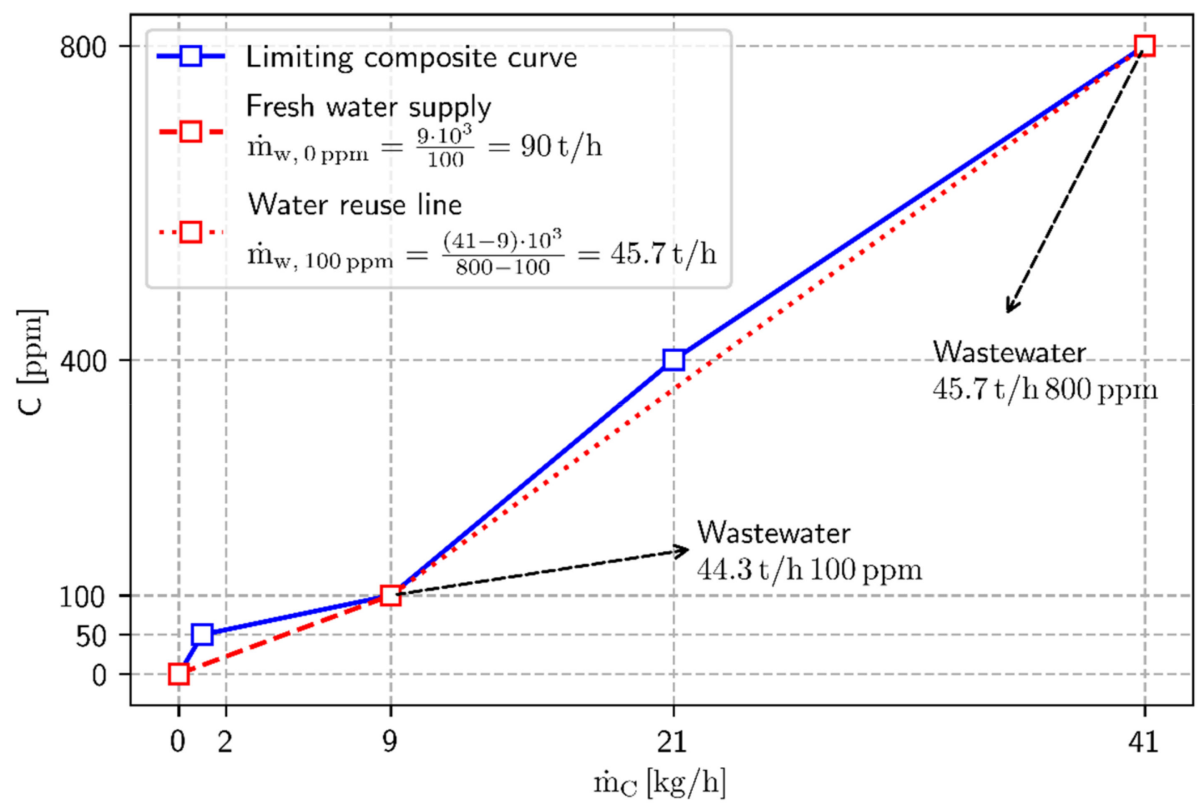

Figure 11. Combination of water demand line and water supply line.

\section{Water Pinch Analysis in the Food Industry}

In the following section, we mainly focus on different aspects of water pinch analysis as implemented in the food sector. First, a review of current practices for water management in the food industry is mentioned. The aim is to know more about the current methods used for water management in food industries. After that, potential of water pinch analysis in the food industry has been considered and examples of this method presented as well. Finally, R\&D needs and challenges are discussed to find the research gaps.

\subsection{Current Practices for Water Management in the Food Industry}

Based on the literature about water management practices in the food sector, Casani and Knøchel [80] were the first to develop a generic model based on hazard analysis critical control point (HACCP) for the implementation of water reuse in the food industry to solve the main barrier of reuse opportunity which was called risk of microbiological contamination of food and environment. After that Casani and Knøchel [81], discussed about reuse challenges in food industries, where on the one hand food safety and consumers' health is a critical issue and on another hand there is limited opportunity of water reuse in the food industry, thanks to regulations that lead to the loss of any big water saving capacity. They discussed different water treatment methods in two main categories: chemicals like chlorine, etc. and physical methods like membrane processes, etc. and they already collected opportunities of reuse within different food industry processes like egg, milk, production, etc. Finally they categorized all reuse issues in food industries in eight sections: environmental, economical, legislation, technological, water quality assessment, social, food industry and academia and counted the drivers, barriers and solutions in the way of water reuse opportunities in food industries. As a result, using HACCP in food systems is highly recommended by the authors. Implementation of HACCP management systems in a dairy plant was already proposed [82]. Using this technique leads to the identification of critical control points (freezing and pasteurization) and in parallel guarantee the food safety and provides improvements at the managerial level. Wujie et al [83], considered the effect of water quality on food quality, the taking into account treatment opportunities in parallel. Various treatment methods like filtration, water softening, etc. have been reviewed.

In other work, Compton et al. [84], studied the food processing industry from energy, fuel, and water consuming perspectives. Because of the nature of this type of industry they consume huge amounts of energy and water. In Compton and his collegues' opinion, to stay in the market and be 
economic, it seems necessary to implement some high-tech technologies like membrane separation, high-pressure processing, microwave assistance, etc. as these technologies help industries increase their efficiency and save them money in dynamic markets.

In the work of Lee and Okos [85] the authors tried to propose strategies for food processing industries to achieve zero discharge and reductions in the use of energy and freshwater in parallel. In this way they consider three different food industries (edible beans, dairy, and corn) and three approaches are proposed to reach the goals: first is plant-scale audit data collection, the second is laboratory-scale experiments and the third computer-aided simulation to design systems. Implementation of these approaches in food case studies leads to a considerable reduction in water and energy use and also wastewater generation. Buabeng-Baidoo et al. [76], worked on reuse opportunities in the dairy industry where they focused on process integration tools. Based on their case study, the cleaning-in-place (CIP) phase uses a significant volume of water (more than $70 \%$ ) in the factory, so for this reason they focused on CIP operations. In this article techniques like reverse osmosis (RO) membranes and in parallel mathematical programming (mix-integer nonlinear (MINLP)) techniques have been applied. As a result, a $33 \%$ reduction for water and $85 \%$ reduction in wastewater production have been reported. Meneses et al. [86], work reviews water reuse challenges in the food industry. They believe that in the food sector, irrigation is the highest water demanding stage. It mentioned that food processing uses a huge percentage of high-quality freshwater and produces a big amount of wastewater because of its nature, so it's a key step in the food supply chain. As a result, comprehensive evaluations considering all aspects like cost, risk and environmental performance are highly recommended.

Suárez et al. [87] and Suárez and Riera [88], did two separate research studies in the dairy industry, where the main technique which was implemented was $\mathrm{RO}$ to recover wastewater and to produce high-quality water. In the first article, they considered three main parameters: $\mathrm{pH}, \mathrm{COD}$, and conductivity as pollutant indicators. In the end they proposed a post-treatment to adjust the $\mathrm{pH}$, and a 2.2-year payback period has been considered for treatment instruments. In the other work the main focus was on milk dairy condensates, and they considered COD and conductivity as indicators. A 90\% recovery rate with a 1.16 year payback period has been reached as a main result.

Based on the literature, there are different groups of articles with different points of view. In some of them, methods to reduce freshwater consumption and wastewater generation in parallel are presented, and in other groups of articles they count the challenges in the way of reuse, recycle and regeneration of water in the food industry by considering the limitations, regulations, and hazards due to food safety and the importance of using high-quality water in these special kinds of industries. In this review a lack of implementation of the water pinch method for food industries seems obvious (or there is no comprehensive work with pinch as its main focus). In the next section the potential of water pinch analysis in the food industry has been considered and an in-depth discussion presented based on applying water pinch studies to this sector.

\subsection{Potential of Water Pinch Analysis in the Food Industry (New Tools for New Approaches)}

Water is a unique resource for the food processing industry for which there are no alternatives. In order to ensure food safety, food and drink processes require a stable and high-quality water supply. Given the diversity of organic processed products, a large amount of liquid effluent is produced. The management of effluent is of the highest importance because of the environmental impact of the wastewater. The most important environmental impacts include eutrophication and asphyxiation of aquatic environments, due to highly polluted effluents with organic carbon, nitrogen, and phosphorus. For example, the BOD and COD levels in food industry wastewaters can be 10-100 times higher than those of domestic wastewater. Therefore, food industry water use and wastewater discharge are both subject to stringent environmental regulation and require appropriate treatment. In addition to the cost of feed water, the treatment cost is the most important operating cost. The annual cost of these integration techniques is on average three million euros [9]. 
Each process in the food industry has its own unique and specific features. Some processes are intermittent and highly dependent on the availability of a feedstock (e.g., sugar factories, fruit, and vegetable processing). In contrast, the dairy industry operates seven days a week for the whole year. Some other processes operate continuously or nearly continuously (e.g., breweries, wineries, etc.). All these features involve diverse using-water operation and sources of freshwater. In food production, water is used for general purposes, such as cleaning, soaking, blanching, chilling; cooling/heating, or also as an extracting agent (e.g., extraction of sugar from sliced beet). Generally, in the food industry, only properly treated potable water should be used. Often, the source of water comes from municipal plants (public water), or sometimes it comes from in-situ drilling, rainwater and recycled water to different levels for various operations. In all cases, the water must satisfy the standards required for drinking water, but additional treatments are required in order to meet the strict quality specifications of food production. For example, in breweries, process water must not contain any organic substances to avoid microbial growth and, consequently, affect the quality of the beer. In a sugar refinery, the presence of inorganic substances is not allowed (e.g., hydrogen carbonates, iron, manganese, nitrates, nitrites and sulphates).

The pinch analysis applied to water makes it possible to identify ways leading to a minimal use of water in the plant and the minimization of water effluents. Economically, it is interesting to reduce the investments required to increase the production rate of the plant by saving water and by reducing the effluent to be treated. These analyses can be applied to most of the processes in the agro-food industries that involve high consumption of water and the production of wastewater. Despite the development of pinch mass analysis in many studies, this technique still occupies a small place in industry, particularly in the food sector. There are different challenges in the implementation of this method in the agro-food industries sector. Normal food industries are large scale and have a complex water system, in addition to this, the number of pollutants is not just one and scientists are faced with multi-contaminant systems. By taking into account the purity constraints for several pollutants the pinch method requires the use of mathematical tools such as multi-objective optimization. This means that the implementation of this method in the real case of agro-food industries normally requires complex mathematical work and optimization tools which are hard to use in nature. Development of a new generic method for water/wastewater minimization and water network design, based on water pinch analysis seems necessary. It has to be suitable for agro-food processes and should therefore be able to handle either single or multi-contaminant flows.

For the implementation of the water pinch method in agro-food industries, it's necessary to know the nature of each operation in different case studies. This information helps us to have more accurate results. To understand the situation of this categorization and find the type of operations in different case studies three types of food industries have been considered (brewery, citrus and sugar industries). Generally, there is two types of water-using operations: mass transfer-based operations and non-mass transfer-based operations. In mass transfer-based operations, the bulk pick-up of contaminants in the water occurs through direct contact between the water, the equipment walls and/or the processed material. Vessel washing operations and wet scrubber operations are two examples of mass transfer-based operations. In non-mass transfer-based operations, the water is used as an energy utility, reactant or product of a chemical reaction. Using water in cooling towers and evapo-concentration are two examples of non-mass transfer-based operations. As a result, in breweries and the citrus industries, most of the operations are mass transfer-based operations and in the sugar industry the two categories have approximately the same contribution. Detailed information is presented in the next paragraphs.

Based on the work in the brewery industry [7], there are different operations of which $18 \%$ are non-mass transfer-based operations and $82 \%$ are mass transfer-based operations. Each of these categories presents some operations and each operation consumes a certain amount of water. In the non-mass transfer-based section there are four main operations that need water, namely water preparation (about $14 \%$ ), air compressors \& $\mathrm{CO}_{2}$ (less than $3 \%$ ), evaporative cooling towers (up to 
$32 \%$ ) and boilers (about 9\%) and in the mass transfer-based section there are five main operations that need water which are keg washing (about $12 \%$ ), bottle washing (up to $33 \%$ ), maturation (about 11\%), fermentation (about 26\%) and CIP (about13\%).

To understand the exact categorization of mass and non-mass transfer-based operations in a citrus plant, it's necessary to explain the operations and schematics of this kind of industry. In terms of a typical citrus plant, there are three main steps which are named selection and cleaning, extraction plant and treatment operations which contains three subsection (peel, juice, and emulsion). This schematic presents the principle of a citrus plant, but to be more aware of the type of operation (mass or non-mass transfer-based operations). The main operations are aligned in the real order of the plant: packing, treatment plant (potable) \& boiler, selection/cleaning, APV condenser \& green tank, vacuum pump, screen, finisher, distiller, screen 1, distiller condenser \& washing spiral 1 and centrifuge. Based on the explanation about the categorization of mass and non-mass transfer-based operations in the citrus plant, the results show that most of the operations (64\%) are mass transfer-based ones and the rest are non-mass transfer- based operations.

To understand the exact categorization for mass and non-mass transfer based operation in the sugar industry, it is necessary to explain the operations and schematics of this kind of industry [89]. There are seven main steps in a typical sugar industry. The main operations are sorted in the real order of the plant: sugarcane preparation and juice extraction, juice treatment, juice evaporation, sugar boiling, crystallization, centrifugal separation and drying, fermentation, distillation, condensate tank, and water cooling system. Based on the explanations about the categorization of mass and non-mass transfer-based operations in the sugar industry, the results show that most of the operations (up to $55 \%$ ) are mass transfer-based ones and the rest are non-mass transfer-based operations.

Applying water pinch analysis has some economic aspects in addition to saving fresh water. Based on the results for four types of food industries (citrus, sugar, fruit juice and brewery) which are presented in Table 6 there are economic savings in investments ranging from 23\% to $69 \%$ with different attractive payback periods ranging from 5 days to 4 months which show the economic benefits of using this method in addition to environmental and other benefits. In the following table different type of operations (continuous and batch) have been considered to demonstrate the flexibility of the applicability of this method for different types of operations. Another issue is the number of indicators used in each case study. Both single and multi-contaminant systems have been considered to do this analysis.

Table 6. Examples of savings identified by applying mass pinch analysis.

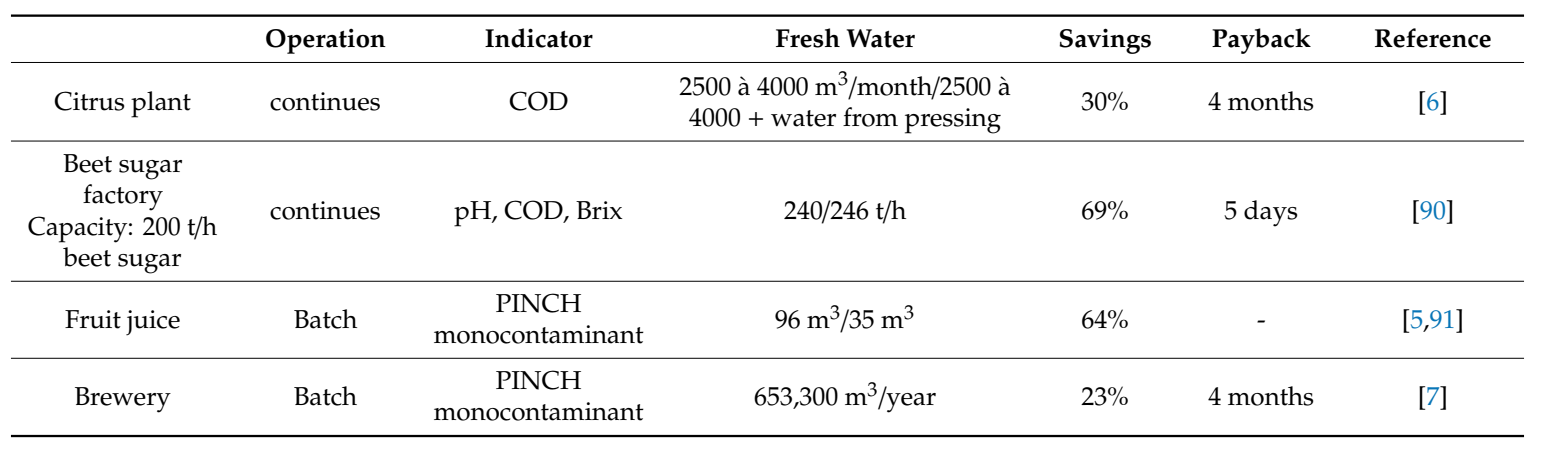

Based on the literature, applying water pinch to different food sectors like dairy, beverage (including the citrus and food juice industry), etc. has an impressive effect on reduction of fresh water use and wastewater production. The average reduction range of freshwater use in the different food sector is between $27 \%$ and up to $65 \%$ for the beverage sector and palm oil mill industries, respectively. In parallel, information concerning the average amount of wastewater produced in different food sectors is presented in Figure 12. The average reduction ranges of wastewater produced in the different food sectors is between $28 \%$ which corresponds to the beverage sector up to $75 \%$ in the dairy industries. 


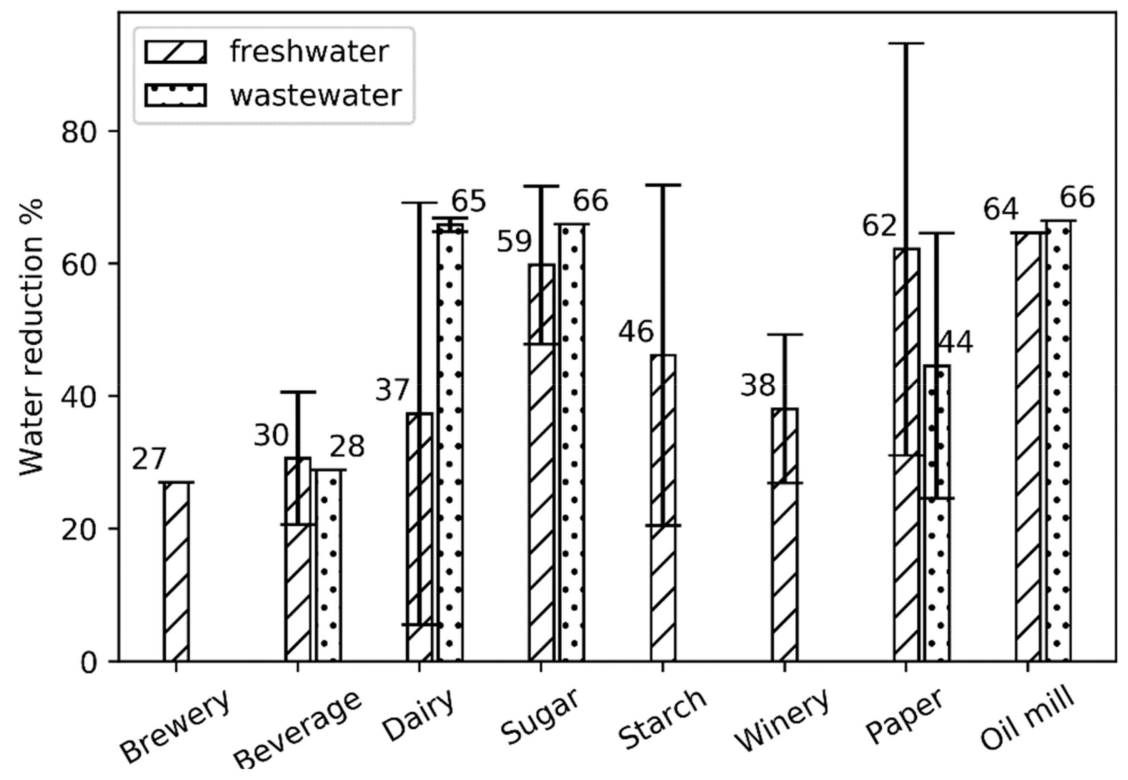

Figure 12. Average freshwater/wastewater consummation/production reduction based on different food sectors.

Based on the discussion in this section, the importance of using water pinch in the food industry has been shown clearly. There are different challenges to face to implement this method and obtain impressive savings of water and reduction of wastewater production. In the next section, the discussion will be on R\&D needs and challenges for implementing water pinch in agro-food industries.

\subsection{RED Needs and Challenges}

In the previous section, a comprehensive literature survey about the milestones of water pinch, functions, graphical examples and in depth discussion about using water pinch in the food industry has been presented. In addition, some useful information about the type of operation (mass transfer-based operations and non-mass transfer-based operations) in different case studies like brewery, citrus, and sugar industries has been extracted. Thanks to the examples about the implementation of water pinch in the previous section and also the challenges mentioned before, it's necessary to obtain by measurement or simulation the required data for this method. Some of this information can be obtained directly from industrial site measurements and some of them are standards and specific data from the literature. The required data can also be obtained by numerical simulation. Normally, it is necessary to know the type and number of pollutant indicators, limiting water data like limiting concentration, the minimum and maximum water flow rate in input and output and threshold values of pollutant indicator for each operation, etc. while another issue is about the type of process. There are different process types like batch, continuous or semi-continuous. To implement the pinch method in the food sector finding the process type is vital. A big part of industries have continuous process operations and the pinch method is normally developed for this type of process in the literature, but in reality, there are also batch or semi-continuous type processes in the food sector. One of the challenges is to propose an adapted model for all types of processes which can be a good subject for further researches.

Based on the information extracted from database articles, some results are obtained and presented below. The frequency of use for different pollutant indicators in different sectors of the food industry is collected in Table 6. This table gives useful guidelines about the utilization of indicators in each industry, for example, in the dairy industry, the most used indicator is microbial count which is used five times, followed by electrical conductivity (EC) three times and also COD and turbidity, each used twice. For the sugar industry, the most frequent indicator is COD and four other indicators like $\mathrm{pH}$, BOD, microbial count, and turbidity are in the next level of importance. For the meat processing 
industry microbial count is the most important one and for the paper industry it is the TDS. For other industries the priorities are aligned in the following order: in the brewery industry $\mathrm{COD}, \mathrm{pH}$ and $\mathrm{EC}$, in the citrus industry COD, $\mathrm{pH}$ and TSS, in the ethanol sector COD, $\mathrm{pH}, \mathrm{BOD}$ and $\mathrm{OG}$, for the starch industry TSS, TDS, TOC and for the winery industry COD and TSS are the most important indicators that have the same priority based on their frequency of use in the literature. Based on the information presented in Figure 13, it's easy to find which indicator will be more effective to develop a water pinch method considering the pollutant indicators.

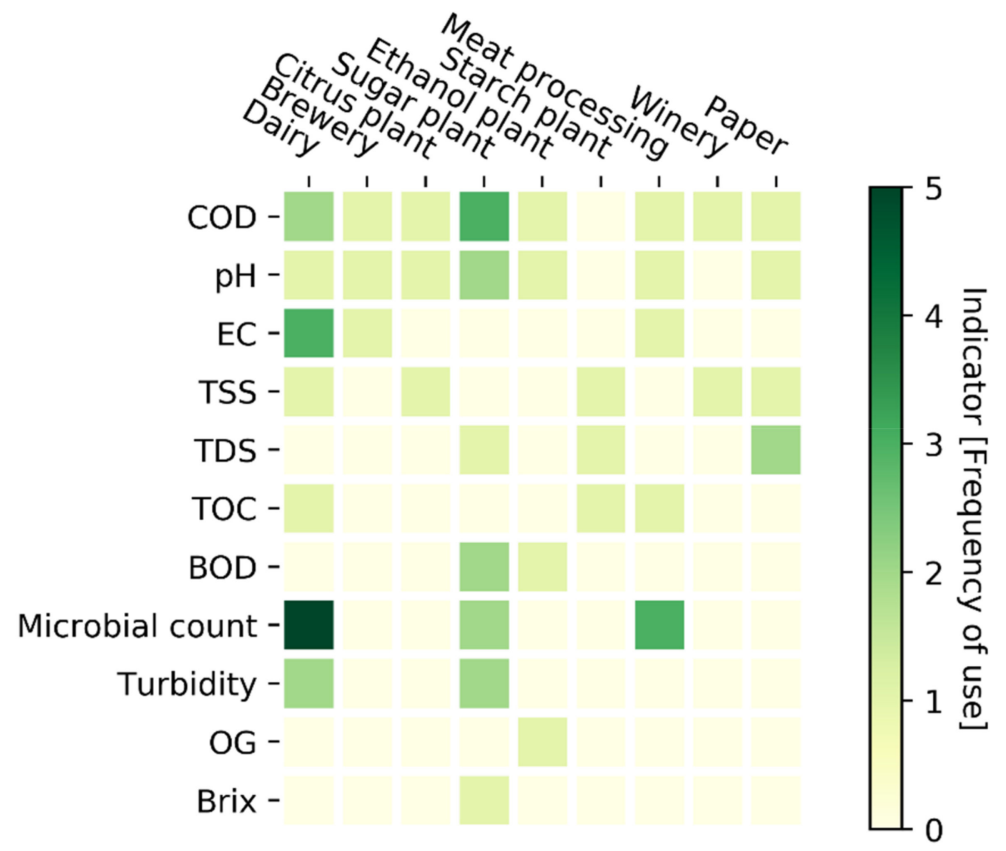

Figure 13. Detailed analysis of the frequency of use indicators.

The choice of one or more pollution indicators is in itself an important challenge given the variety of processes in the food industry. Often, various constraints are merged, including the consideration of food safety, too strict regulations and environmental issues. Process management in this sector is not as flexible as regulatory constraints often prohibit the reuse of water of lower quality, despite the availability of water and the potential of water reuse within factories. The development of pinch analysis must take into account these considerations by determining the minimum required water quality and by screening solutions that integrate risk assessment. Pinch analysis should also be considered as a means of promoting advantageous solutions and why not a means to argue changes in the standards and guidelines in the food industry (up to now too strict and not flexible).

Another challenge is how to provide not only effective and safe food security solutions but also sustainable solutions. A fundamental challenge of sustainable development is to provide a water network without any further unacceptable levels of environmental degradation. For example, if the water network proposed by the pinch involves regeneration steps, in this case, some inputs are required (e.g., chemical solvents, energy resources, etc.). It is, therefore, necessary to analyze the environmental efficiency of the solutions provided by the pinch by integrating LCA or water footprint analysis.

\section{Conclusions}

There are some reasons why the food industry faces the challenge of reducing water consumption. These are environmental problems, investment, regulation, sanitary safety (and thus water quality), as well as social problems. Water consumption and wastewater generation in the food industry could be minimized by replacing the existing technologies with new ones. However, setting up innovative equipment will require a lot of investment and R\&D time. In addition, regarding the low price of 
water, investment for purification equipment is unjustified. Optimizing water networks through pinch analysis is an opportunity to increase the efficiency of water use in the food industry with lower investment costs. The pinch analysis applied to water provides a reduction of water consumption ranging from 20 to $40 \%$ at a reduced cost. Its development and availability for the food industry should encourage manufacturers to adopt this approach and achieve water savings. The key idea for minimizing water with pinch analysis is to identify streams of water that can be reused in an operation for which water quality is acceptable. Minimum water requirements can be targeted using graphical tools or automated design methods. The earlier graphical targeting methods provide a conceptual insight into the problem and highlighted the proper designs. Although, when other components are added to the problem and consequently the need for cost optimization is risen up, these problems become too complicated for these graphical targeting procedures. As a challenge, data extraction is the most critical step for performing an optimal analysis. Most of the methods discussed in the literature are based on single-contaminant water systems. Considering single water contaminants and the limited number of water sources with a simple framework is suitable to present how water pinch analysis work, however, many contaminants must be taken into account.

In the food industry, it is almost impossible to include all the components that influence water chemistry, the microbiological aspect and the quality of the food product. In some food processing sectors, it is common to select representative contamination indicators. The application of the graphical method for multi-contaminant water systems is not easily manipulated. For this, the development of numerical tools seems a crucial step for the development of pinch analysis and its application in the food industry. It seems that the trend is towards using methods such as mathematical programming in order to solve complex problems. Mathematical programming is not without difficulty as non-linear problems are often non-convex. It means that global optima are often not obtained. Recently, a large amount of research has been devoted to this area. In this dissertation, some software like MATLAB ${ }^{\circledR}$ or PYTHON ${ }^{\circledR}$, etc. rely on mathematical programming techniques, and offer graphical insights that provide easy to understand solutions. When considering the nature of multi-contaminant mathematical models to solve these models normally the development of multi-criteria optimization methods seems necessary. Multi-objective and multi-constraint optimization tools, especially evolutionary methods (GA, PSO, etc.) seem helpful to solve this kind of problem.

As a further research proposition, development of an integrated tool which includes water pinch analysis, energy pinch analysis and also life cycle assessment (LCA) seems necessary. Within this integrated tool, it's would be possible to improve the energy and water use efficiency and also consider the environmental aspects by taking to account the LCA technique. Another proposition is about new solving procedures. As mentioned before, to solve multi-contaminant system models, the use of evolutionary methods seems necessary. Testing new evolutionary methods instead of traditional ones (GA, PSO, etc.) could be interesting.

Author Contributions: K.N.-A., H.R. and M.-L.L. conceived the idea and the structure of the presented review. K.N.-A. developed the bibliographic research. H.R. developed the illustrations and the corresponding figures. H.R. and M.-L.L. supervised the project and provided critical feedback.

Funding: This work is part of the MINIMEAU project (minimization of water consumption in agro-food industries by developing a combined approach integrating Water Footprint and Pinch methods), and supported by the French National Research Agency (ANR).

Conflicts of Interest: The authors declare no conflict of interest. 


\section{Nomenclature}

\begin{tabular}{|c|c|c|}
\hline Roman & Uppercase & Letters \\
\hline BOD & Biochemical Oxygen Demand & \\
\hline Brix & sugar content & $\mathrm{Bx}$ \\
\hline $\mathrm{C}$ & cold stream/concentration & \\
\hline COD & Chemical Oxygen Demand & \\
\hline$C P$ & Heat capacity flowrate & $\mathrm{Kw} / \mathrm{K}$ \\
\hline$C_{p}$ & Specific heat & $\mathrm{Kj} / \mathrm{kg} / \mathrm{K}$ \\
\hline $\mathrm{EC}$ & electrical conductivity & $\mathrm{S} / \mathrm{m}$ \\
\hline GA & Genetic Algorithm & \\
\hline GAMS & General Algebraic Modeling System & \\
\hline $\mathrm{H}$ & Hot stream & \\
\hline ISO 14000 & Environmental standard management & \\
\hline ISO 50001 & Energy standard management & \\
\hline LP & Linear Programing & \\
\hline MATLAB & numerical computing environment & \\
\hline MILP & Mix Integer Linear Programing & \\
\hline MINLP & Mix Integer Non-Linear Programing & \\
\hline MSA & Mass Separating Agents & \\
\hline NLP & Non-Linear Programing & \\
\hline PSO & Particle Swarm Optimization & \\
\hline Python & Programming language & \\
\hline OG & Oils and Grease & \\
\hline $\mathrm{T}$ & Temperature & ${ }^{\circ} \mathrm{C}$ \\
\hline TDS & Total Dissolved Solids & \\
\hline TOC & Total Organic Carbon & \\
\hline TSS & Total Suspend Solid & \\
\hline AFI & Agro-Food Industry & \\
\hline WPA & Water Pinch Analysis & \\
\hline $\mathrm{pH}$ & Acidity Or Basicity & \\
\hline BOD5 & 5 Days Biological Oxygen Demand & \\
\hline $\mathrm{R} 2 \mathrm{~A}$ & Reasoner's 2A Agar & \\
\hline DR & Dry Residues & \\
\hline NF & Nanofiltration Stage & \\
\hline $\mathrm{RO}$ & Reverse Osmosis & \\
\hline AOX & Absorbable Organic Halides & \\
\hline $\mathrm{HP}$ & Hardness Properties & \\
\hline POME & Palm Oil Mill Effluent & \\
\hline $\mathrm{HC}$ & Hydrocarbon & \\
\hline WIN & Water Use Index & \\
\hline EIN & Environmental Performance Index & \\
\hline AFI & Agro Food Industry & \\
\hline HEN & Heat Exchanger Network & \\
\hline MEN & Mass Exchanger Network & \\
\hline MSA & Mass Separating Agents & \\
\hline LCA & Life Cycle Assessment & \\
\hline FU & Functional Unit (e.g., kg of processed milk) & \\
\hline WEUI & Water And Energy Use Indicator & \\
\hline IPPC & Integrated Pollution Prevention and Control & \\
\hline $\mathrm{U}$ & unit & \\
\hline
\end{tabular}




$\begin{array}{llc}\begin{array}{l}\text { Roman } \\ \text { Emergy }\end{array} & \begin{array}{l}\text { Lowercase } \\ \text { embodied solar energy }\end{array} & \text { Letters } \\ \dot{m} & \text { mass flowrate } & \mathrm{kg} / \mathrm{s} \\ \mathrm{pH} & \text { acidity or basicity } & \\ \text { Greek Letters } & & \mathrm{kJ} / \mathrm{kg} \\ \Delta H & \text { Latent heat } & { }^{\circ} \mathrm{C} \\ \Delta T & \text { Temperature difference } & \\ \text { Subscripts } & & \\ \text { in } & \text { input } & \\ \text { min } & \text { minimum } & \\ \mathrm{o} & \text { output } & \\ \mathrm{s} & \text { supply } & \\ \mathrm{t} & \text { target } & \\ \mathrm{w} & \text { water } & \end{array}$

\section{References}

1. Linnhoff, B.; Flower, J.R. Synthesis of Heat Exchanger Networks: I. Systematic Generation of Energy Optimal Networks. AIChE J. 1978, 24, 633-642. [CrossRef]

2. Wang, Y.P.; Smith, R. Wastewater Minimisation. Chem. Eng. Sci. 1994, 49, 981-1006. [CrossRef]

3. El-Halwagi, M.M.; Gabriel, F.; Harell, D. Rigorous Graphical Targeting for Resource Conservation via Material Recycle/Reuse Networks. Ind. Eng. Chem. Res. 2003, 42, 4319-4328. [CrossRef]

4. Prakash, R.; Shenoy, U.V. Targeting and design of water networks for fixed flowrate and fixed contaminant load operations. Chem. Eng. Sci. 2005, 60, 255-268. [CrossRef]

5. Almató, M.; Sanmartí, E.; Espun, A.; Puigjaner, L. Rationalizing the Water Use in the Batch Process Industry. Comput. Chem. Eng. 1997, 21, 971-976. [CrossRef]

6. Thevendiraraj, S.; Klemeš, J.; Paz, D.; Aso, G.; Cardenas, G.J. Water and wastewater minimisation study of a citrus plant. Resour. Conserv. Recycl. 2003, 37, 227-250. [CrossRef]

7. Tokos, H.; Pintarič, Z.N. Synthesis of batch water network for a brewery plant. J. Clean. Prod. 2009, 17, 1465-1479. [CrossRef]

8. Bavar, M.; Sarrafzadeh, M.H.; Asgharnejad, H.; Norouzi-Firouz, H. Water management methods in food industry: Corn refinery as a case study. J. Food Eng. 2018, 238, 78-84. [CrossRef]

9. Klemes, J.; Friedler, F.; Bulatov, I.; Varbanov, P. Sustainibility in the Process Industry: Integration and Optimization (Green Manufacturing E Systems Engineering); McGraw-Hill Professional: New York, NY, USA, 2010.

10. Alves, J. Analysis and Design of Refinery Hydrogen Distribution Systems. 1999. Available online: http://ethos.bl.uk/OrderDetails.do?uin=uk.bl.ethos.563097 (accessed on 19 August 2018).

11. Zhelev, T.; Ntlhakana, J. Energy-environment closed-loop through Oxygen Pinch. Comput. Chem. Eng. 1999, 23, S79-S83. [CrossRef]

12. Odum, H.T. Systems Ecology: An Introduction; John Wiley and Sons: New York, NY, USA, 1983.

13. Zhelev, T.K.; Ridolfi, R. Energy Recovery and Environmental Concerns Addressed through Emergy-Pinch Analysis. Energy 2006, 31, 2486-2498. [CrossRef]

14. Linnhoff, B.; Dhole, V.R. Targeting for CO2 emissions for Total Sites. Chem. Eng. Technol. 1993, 16, $252-259$. [CrossRef]

15. Tan, R.R.; Foo, D.C. Pinch analysis approach to carbon-constrained energy sector planning. Energy 2007, 32, 1422-1429. [CrossRef]

16. Zhelev, T.K. On the Integrated Management of Industrial Resources Incorporating Finances. J. Clean. Prod. 2005, 13, 469-474. [CrossRef]

17. Linnhoff, B.; Hindmarsh, E. The pinch design method for heat exchanger networks. Chem. Eng. Sci. 1983, 38, 745-763. [CrossRef]

18. El-Halwagi, M.M.; Manousiouthakis, V. Simultaneous synthesis of mass-exchange and regeneration networks. AIChE J. 1990, 36, 1209-1219. [CrossRef]

19. Hallale, N.; Fraser, D. Capital cost targets for mass exchange networks A special case: Water minimisation. Chem. Eng. Sci. 1998, 53, 293-313. [CrossRef] 
20. Hallale, N.; Fraser, D.M. Capital and Total Cost Targets for Mass Exchange Networks: Part 1: Simple Capital Cost Models. Comput. Chem. Eng. 2000, 23, 1661-1679. [CrossRef]

21. Akpomiemie, M.O.; Smith, R. Retrofit of heat exchanger networks without topology modifications and additional heat transfer area. Appl. Energy 2015, 159, 381-390. [CrossRef]

22. Akpomiemie, M.O.; Smith, R. Retrofit of Heat Exchanger Networks with Heat Transfer Enhancement Based on an Area Ratio Approach. Appl. Energy 2015, 165, 22-35. [CrossRef]

23. Akpomiemie, M.O.; Smith, R. Cost-Effective Strategy for Heat Exchanger Network Retrofit. Energy 2018, 146, 82-97. [CrossRef]

24. Wang, Y.; Pan, M.; Bulatov, I.; Smith, R.; Kim, J.K. Application of intensified heat transfer for the retrofit of heat exchanger network. Appl. Energy 2012, 89, 45-59. [CrossRef]

25. Jiang, N.; Shelley, J.D.; Doyle, S.; Smith, R. Heat exchanger network retrofit with a fixed network structure. Appl. Energy 2014, 127, 25-33. [CrossRef]

26. Gadalla, M.A. A new graphical method for Pinch Analysis applications: Heat exchanger network retrofit and energy integration. Energy 2015, 81, 159-174. [CrossRef]

27. Zhang, H.; Rangaiah, G. One-step approach for heat exchanger network retrofitting using integrated differential evolution. Comput. Chem. Eng. 2013, 50, 92-104. [CrossRef]

28. Lee, S.C.; Ng, D.K.S.; Foo, D.C.Y.; Tan, R.R. Extended pinch targeting techniques for carbon-constrained energy sector planning. Appl. Energy 2009, 86, 60-67. [CrossRef]

29. Diamante, J.A.R.; Tan, R.R.; Foo, D.C.; Ng, D.K.S.; Aviso, K.B.; Bandyopadhyay, S. Unified pinch approach for targeting of carbon capture and storage (CCS) systems with multiple time periods and regions. J. Clean. Prod. 2014, 71, 67-74. [CrossRef]

30. Ooi, R.E.; Foo, D.C.; Ng, D.K.S.; Tan, R.R. Planning of carbon capture and storage with pinch analysis techniques. Chem. Eng. Res. Des. 2013, 91, 2721-2731. [CrossRef]

31. Ho, W.S.; Tan, S.T.; Hashim, H.; Lim, J.S.; Lee, C.T. Waste Management Pinch Analysis (WAMPA) for Carbon Emission Reduction. Energy Procedia 2015, 75, 2448-2453. [CrossRef]

32. Crilly, D.; Zhelev, T. Emissions targeting and planning: An application of $\mathrm{CO} 2$ emissions pinch analysis (CEPA) to the Irish electricity generation sector. Energy 2008, 33, 1498-1507. [CrossRef]

33. Atkins, M.J.; Morrison, A.S.; Walmsley, M.R. Carbon Emissions Pinch Analysis (CEPA) for emissions reduction in the New Zealand electricity sector. Appl. Energy 2010, 87, 982-987. [CrossRef]

34. Tan, R.R.; Aviso, K.B.; Foo, D.C. Carbon emissions pinch analysis of economic systems. J. Clean. Prod. 2018, 182, 863-871. [CrossRef]

35. Hallale, N.; Liu, F. Refinery hydrogen management for clean fuels production. Adv. Environ. Res. 2001, 6, 81-98. [CrossRef]

36. Ding, Y.; Feng, X.; Chu, K.H. Optimization of hydrogen distribution systems with pressure constraints. J. Clean. Prod. 2011, 19, 204-211. [CrossRef]

37. Kim, J.; Lee, Y.; Moon, I. Optimization of a hydrogen supply chain under demand uncertainty. Int. J. Hydrogen Energy 2008, 33, 4715-4729. [CrossRef]

38. Jiao, Y.; Su, H.; Hou, W. Improved optimization methods for refinery hydrogen network and their applications. Control. Eng. Pract. 2012, 20, 1075-1093. [CrossRef]

39. Jiao, Y.; Su, H.; Hou, W.; Liao, Z. Optimization of refinery hydrogen network based on chance constrained programming. Chem. Eng. Res. Des. 2012, 90, 1553-1567. [CrossRef]

40. Deng, C.; Zhou, Y.; Jiang, W.; Feng, X. Optimal design of inter-plant hydrogen network with purification reuse/recycle. Int. J. Hydrogen Energy 2017, 42, 19984-20002. [CrossRef]

41. Alves, J.J.; Towler, G.P. Analysis of Refinery Hydrogen Distribution Systems. Ind. Eng. Chem. Res. 2002, 41, 5759-5769. [CrossRef]

42. Zhelev, T.K.; Bhaw, N. Combined water-oxygen pinch analysis for better wastewater treatment management. Waste Manag. 2000, 20, 665-670. [CrossRef]

43. Zhelev, T. Wastewater Treatment Management Using Combined Water-Oxygen-Thermal Pinch Analysis. Comput. Aided Chem. Eng. 2002, 10, 391-396. [CrossRef]

44. Marchettini, N.; Ridolfi, R.; Rustici, M. An environmental analysis for comparing waste management options and strategies. Waste Manag. 2007, 27, 562-571. [CrossRef] 
45. Seider, W.D.; Seader, J.D.; Lewin, D.R. Process Design Principles: Synthesis, Analysis, and Evaluation. 1999. Available online: https://scholar.google.fr/scholar?hl=fr\&as_sdt=0\%2C5\&q=\%28Seider\%2C+Seader+et+al. $+1999 \% 29 \& b \operatorname{tnG}=$ (accessed on 19 August 2018).

46. Hau, J.L.; Bakshi, B.R. Promise and problems of emergy analysis. Ecol. Model. 2004, 178, 215-225. [CrossRef]

47. Pan, H.; Zhang, X.; Wu, J.; Zhang, Y.; Lin, L.; Yang, G.; Deng, S.; Li, L.; Yu, X.; Qi, H.; et al. Sustainability evaluation of a steel production system in China based on emergy. J. Clean. Prod. 2016, 112, 1498-1509. [CrossRef]

48. Zhang, H.; Guan, X.; Ding, Y.; Liu, C. Emergy analysis of Organic Rankine Cycle (ORC) for waste heat power generation. J. Clean. Prod. 2018, 183, 1207-1215. [CrossRef]

49. Arya, D.; Santanu, B. Iterative Pinch Analysis to Address Non-Linearity in a Stochastic Pinch Problem. J. Clean. Prod. 2019, 227, 543-553. [CrossRef]

50. Roychaudhuri, P.S.; Kazantzi, V.; Foo, D.C.; Tan, R.R.; Bandyopadhyay, S. Selection of energy conservation projects through Financial Pinch Analysis. Energy 2017, 138, 602-615. [CrossRef]

51. Roychaudhuri, P.S.; Bandyopadhyay, S. Financial Pinch Analysis: Minimum opportunity cost targeting algorithm. J. Environ. Manag. 2018, 212, 88-98. [CrossRef]

52. Linnhoff, B.; Flower, J.R. Synthesis of Heat Exchanger Networks: II. Evolutionary Generation of Networks with Various Criteria of Optimality. AIChE J. 1978, 24, 642-654. [CrossRef]

53. Takama, N.; Kuriyama, T.; Shiroko, K.; Umeda, T. Optimal water allocation in a petroleum refinery. Comput. Chem. Eng. 1980, 4, 251-258. [CrossRef]

54. Wang, Y.P.; Smith, R. Design of Distributed Effluent Treatment Systems. Chem. Eng. Sci. 1994, 49, 3127-3145. [CrossRef]

55. Wang, Y.P.; Smith, R. Waste-Water Minimization with Flow-Rate Constraints. Chem. Eng. Res. Des. 1995, 73, 889-904.

56. Bagajewicz, M. A review of recent design procedures for water networks in refineries and process plants. Comput. Chem. Eng. 2000, 24, 2093-2113. [CrossRef]

57. Olesen, S.; Polley, G. A Simple Methodology for the Design of Water Networks Handling Single Contaminants. Chem. Eng. Res. Des. 1997, 75, 420-426. [CrossRef]

58. Kuo, W.C.; Smith, R. Design of Water-Using Systems Involving Regeneration. Process Saf. Environ. Prot. 1998, 76, 94-114. [CrossRef]

59. Kuo, W.C.; Smith, R. Designing for the Interactions Between Water-Use and Effluent Treatment. Chem. Eng. Res. Des. 1998, 76, 287-301. [CrossRef]

60. Kuo, W.C.J.; Smith, R. Effluent Treatment System Design. Chem. Eng. Sci. 1997, 52, 4273-4290. [CrossRef]

61. Castro, P.; Matos, H.; Fernandes, M.C.; Nunes, C.P. Improvements for Mass-Exchange Networks Design. 1999. Available online: http://www.academia.edu/download/45687885/s0009-2509_2898_2900526-02016051625031-1ykyyg8.pdf (accessed on 8 October 2018).

62. Dhole, V.R.; Ramchandani, N.; Tainsh, R.A.; Wasilewski, M. Make Your Process Water Pay for Itself. 1996. Available online: http://search.proquest.com/openview/35cd541d1e076333c359811a0ebb512f/1.pdf?pqorigsite $=$ gscholar\&cbl=41910 (accessed on 8 October 2018).

63. Hallale, N. A new graphical targeting method for water minimisation. Adv. Environ. Res. 2002, 6, 377-390. [CrossRef]

64. Doyle, S.; Smith, R. Targeting Water Reuse with Multiple Contaminants. Process. Saf. Environ. Prot. 1997, 75, 181-189. [CrossRef]

65. Alva-Argáez, A.; Kokossis, A.; Smith, R. Wastewater minimisation of industrial systems using an integrated approach. Comput. Chem. Eng. 1998, 22, 741-744. [CrossRef]

66. Galan, B.; Grossmann, I.E. Optimal Design of Distributed Wastewater Treatment Networks. Ind. Eng. Chem. Res. 1998, 37, 4036-4048. [CrossRef]

67. Huang, C.H.; Chang, C.T.; Ling, H.C.; Chang, H.C. A Mathematical Programming Model for Water Usage and Treatment Network Design. Ind. Eng. Chem. Res. 1999, 38, 2666-2679. [CrossRef]

68. Jödicke, G.; Fischer, U.; Hungerbühler, K. Wastewater reuse: A new approach to screen for designs with minimal total costs. Comput. Chem. Eng. 2001, 25, 203-215. [CrossRef]

69. Feng, X.; Chu, K. Cost Optimization of Industrial Wastewater Reuse Systems. Process. Saf. Environ. Prot. 2004, 82, 249-255. [CrossRef] 
70. Manan, Z.; Alwi, S.W.; Ujang, Z.; Alwi, S.R.W. Water pinch analysis for an urban system: A case study on the Sultan Ismail Mosque at the Universiti Teknologi Malaysia (UTM). Desalination 2006, 194, 52-68. [CrossRef]

71. Tan, Y.; Manan, Z.; Foo, D.; Foo, D. Retrofit of Water Network with Regeneration Using Water Pinch Analysis. Process. Saf. Environ. Prot. 2007, 85, 305-317. [CrossRef]

72. Mohammadnejad, S.; Bidhendi, G.N.; Mehrdadi, N. Water pinch analysis in oil refinery using regeneration reuse and recycling consideration. Desalination 2011, 265, 255-265. [CrossRef]

73. Boix, M.; Montastruc, L.; Pibouleau, L.; Azzaro-Pantel, C.; Domenech, S. A multiobjective optimization framework for multicontaminant industrial water network design. J. Environ. Manag. 2011, 92, 1802-1808. [CrossRef]

74. Almaraz, S.D.L.; Boix, M.; Montastruc, L.; Azzaro-Pantel, C.; Liao, Z.; Domenech, S. Design of a water allocation and energy network for multi-contaminant problems using multi-objective optimization. Process. Saf. Environ. Prot. 2016, 103, 348-364. [CrossRef]

75. Mughees, W.; Al-Ahmad, M. Application of water pinch technology in minimization of water consumption at a refinery. Comput. Chem. Eng. 2015, 73, 34-42. [CrossRef]

76. Buabeng-Baidoo, E.; Mafukidze, N.; Pal, J.; Tiwari, S.; Srinivasan, B.; Majozi, T.; Srinivasan, R. Study of water reuse opportunities in a large-scale milk processing plant through process integration. Chem. Eng. Res. Des. 2017, 121, 81-91. [CrossRef]

77. Li, Y.; Guan, J.; Ying, L.; Jintao, G. A stepwise optimal design of water network. Chin. J. Chem. Eng. 2016, 24, 787-794. [CrossRef]

78. Feng, X.; Bai, J.; Wang, H.; Zheng, X. Grass-roots design of regeneration recycling water networks. Comput. Chem. Eng. 2008, 32, 1892-1907. [CrossRef]

79. Skouteris, G.; Ouki, S.; Foo, D.; Saroj, D.; Altini, M.; Melidis, P.; Cowley, B.; Ells, G.; Palmer, S.; O’Dell, S. Water footprint and water pinch analysis techniques for sustainable water management in the brick-manufacturing industry. J. Clean. Prod. 2018, 172, 786-794. [CrossRef]

80. Casani, S.; Knøchel, S. Application of HACCP to water reuse in the food industry. Food Control. 2002, 13, 315-327. [CrossRef]

81. Casani, S.; Rouhany, M.; Knøchel, S. A discussion paper on challenges and limitations to water reuse and hygiene in the food industry. Water Res. 2005, 39, 1134-1146. [CrossRef]

82. Lu, J.; Pua, X.H.; Liu, C.T.; Chang, C.L.; Cheng, K.C. ScienceDirect The Implementation of HACCP Management System in a Chocolate Ice Cream Plant. J. Food Drug Anal. 2013, 22, 391-398. [CrossRef]

83. Jie, W.; Fei, Z.; Xu, J. The Influence of Water Quality on Food Quality and the Treatment of Water for Food Processing. Procedia Environ. Sci. 2011, 10, 2671-2676. [CrossRef]

84. Compton, M.; Willis, S.; Rezaie, B.; Humes, K. Food Processing Industry Energy and Water Consumption in the Paci Fi c Northwest. Innov. Food Sci. Emerg. Technol. 2018, 47, 371-383. [CrossRef]

85. Lee, W.; Okos, M.R. Sustainable food processing systems-Path to a zero discharge: Reduction of water, waste and energy. Procedia Food Sci. 2011, 1, 1768-1777. [CrossRef]

86. Meneses, Y.E.; Stratton, J.; Flores, R.A. Water reconditioning and reuse in the food processing industry: Current situation and challenges. Trends Food Sci. Technol. 2017, 61, 72-79. [CrossRef]

87. Suárez, A.; Fidalgo, T.; Riera, F.A. Recovery of Dairy Industry Wastewaters by Reverse Osmosis. Sep. Purif. Technol. 2014, 133, 204-211. [CrossRef]

88. Suárez, A.; Riera, F.A. Production of High-Quality Water by Reverse Osmosis of Milk Dairy Condensates. J. Ind. Eng. Chem. 2015, 21, 1340-1349. [CrossRef]

89. Ensinas, A.V.; Nebra, S.A.; Lozano, M.A.; Serra, L.M. Analysis of process steam demand reduction and electricity generation in sugar and ethanol production from sugarcane. Energy Convers. Manag. 2007, 48, 2978-2987. [CrossRef]

90. Žbontar, Z.L.; Glavič, P. Water minimization in process industries: Case study in beet sugar plant. Resour. Conserv. Resour. Conserve. Recycl. 2005, 43, 133-145. [CrossRef]

91. Li, B.-H.; Chang, C.-T. A Mathematical Programming Model for Discontinuous Water-Reuse System Design. Ind. Eng. Chem. Res. 2006, 45, 5027-5036. [CrossRef]

(C) 2019 by the authors. Licensee MDPI, Basel, Switzerland. This article is an open access article distributed under the terms and conditions of the Creative Commons Attribution (CC BY) license (http://creativecommons.org/licenses/by/4.0/). 